\title{
Operando Raman spectroscopy tracks oxidation-state changes in an amorphous Co oxide material for electrocatalysis of the oxygen evolution reaction
}

Cite as: J. Chem. Phys. 152, 194202 (2020); https://doi.org/10.1063/5.0006306

Submitted: 02 March 2020 . Accepted: 27 April 2020 . Published Online: 20 May 2020

(D) Chiara Pasquini, (D) Luca D’Amario, (D) Ivelina Zaharieva, and (D) Holger Dau

\section{COLLECTIONS}

Paper published as part of the special topic on Interfacial Structure and Dynamics for Electrochemical Energy Storage

F This paper was selected as Featured

\section{ARTICLES YOU MAY BE INTERESTED IN}

New aspects of operando Raman spectroscopy applied to electrochemical $\mathrm{CO}_{2}$ reduction on Cu foams

The Journal of Chemical Physics 150, 041718 (2019); https://doi.org/10.1063/1.5054109

How cations affect the electric double layer and the rates and selectivity of electrocatalytic processes

The Journal of Chemical Physics 151, 160902 (2019); https://doi.org/10.1063/1.5124878

The Journal of Chemical Physics ELECTRO2020, 194202 (2020); https://

doi.org/10.1063/5.0006306@jcp.2020.ELECTRO2020.issue-1

Challenge us.

What are your needs for periodic signal detection?

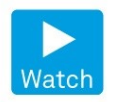

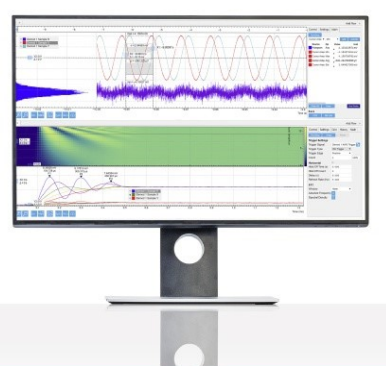

Zurich - Instruments

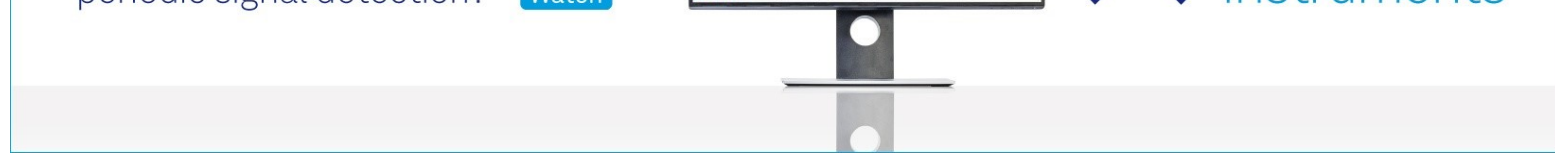




\title{
Operando Raman spectroscopy tracks oxidation-state changes in an amorphous Co oxide material for electrocatalysis of the oxygen evolution reaction
}

\author{
Cite as: J. Chem. Phys. 152, 194202 (2020); doi: 10.1063/5.0006306 \\ Submitted: 2 March 2020 - Accepted: 27 April 2020 • \\ Published Online: 20 May 2020
}

Chiara Pasquini, (D) Luca D’Amario, (D) Ivelina Zaharieva, (D) and Holger Dau ${ }^{\text {a) (D) }}$

\section{AFFILIATIONS}

Department of Physics, Freie Universität Berlin, Arnimallee 14, 14195 Berlin, Germany

Note: This paper is part of the JCP Special Topic on Interfacial Structure and Dynamics for Electrochemical Energy Storage. a) Author to whom correspondence should be addressed: holger.dau@fu-berlin.de

\begin{abstract}
Transition metal oxides are of high interest in both energy storage (batteries) and production of non-fossil fuels by (photo)electrocatalysis. Their functionally crucial charge (oxidation state) changes and electrocatalytic properties are best investigated under electrochemical operation conditions. We established operando Raman spectroscopy for investigation of the atomic structure and oxidation state of a noncrystalline, hydrated, and phosphate-containing Co oxide material (CoCat), which is an electrocatalyst for the oxygen evolution reaction (OER) at neutral $\mathrm{pH}$ and is structurally similar to $\mathrm{LiCoO}_{2}$ of batteries. Raman spectra were collected at various sub-catalytic and catalytic electric potentials. ${ }^{2} \mathrm{H}$ labeling suggests $\mathrm{Co}$ oxidation coupled to $\mathrm{Co}-\mathrm{OH}$ deprotonation at catalytic potentials. ${ }^{18} \mathrm{O}$ labeling supports $\mathrm{O}-\mathrm{O}$ bond formation starting from terminally coordinated oxygen species. Two broad bands around $877 \mathrm{~cm}^{-1}$ and $1077 \mathrm{~cm}^{-1}$ are assigned to CoCat-internal $\mathrm{H}_{2} \mathrm{PO}_{4}{ }^{-}$. Raman peaks corresponding to terminal oxide $(\mathrm{Co}=\mathrm{O})$ or reactive oxygen species were not detectable; $1000-$ $1200 \mathrm{~cm}^{-1}$ bands were instead assigned to two-phonon Raman scattering. At an increasingly positive potential, the intensity of the Raman bands decreased, which is unexpected and explained by self-absorption relating to CoCat electrochromism. A red-shift of the Co-O Raman bands with increasing potentials was described by four Gaussian bands of potential-dependent amplitudes. By linear combination of Raman band amplitudes, we can follow individually the $\mathrm{Co}(2+/ 3+)$ and $\mathrm{Co}(3+/ 4+)$ redox transitions, whereas previously published x-ray absorption spectroscopy analysis could determine only the averaged Co oxidation state. Our results show how electrochemical operando Raman spectroscopy can be employed as a potent analytical tool in mechanistic investigations on OER catalysis.
\end{abstract}

Published under license by AIP Publishing. https://doi.org/10.1063/5.0006306

\section{INTRODUCTION}

Enabling large scale carbon-neutral fuel production is a key point toward solving the global energy crisis. ${ }^{1-4}$ The electrochemical production of molecular hydrogen from $\mathrm{H}_{2} \mathrm{O}$ and the transformation of $\mathrm{CO}_{2}$ in high-energy chemicals are promising approaches. For both cathodic reactions, $\mathrm{H}_{2}$ formation and $\mathrm{CO}_{2}$ reduction, the anodic process is typically water oxidation coupled to $\mathrm{O}_{2}$ formation. Energetic inefficiency (high overpotentials) of the oxygen evolution reaction (OER) often represents a major limitation in the development of efficient water splitting or $\mathrm{CO}_{2}$ reduction devices.
To address the OER bottleneck toward high energetic efficiency, many researchers aim at understanding the mechanism of OER ${ }^{8-}$ and, thus, developing more efficient OER catalysts. ${ }^{14-17}$ In the past decade, catalysts from earth-abundant elements ( $\mathrm{Fe}, \mathrm{Ni}, \mathrm{Co}$, and $\mathrm{Mn}$ ) became a focal point in OER research. ${ }^{18-24}$ These are often transition metal oxide that can (reversibly) accumulate oxidizing equivalents required to extract electrons from $\mathrm{H}_{2} \mathrm{O}$. ${ }^{10,25-28}$

Oxidizing equivalents are accumulated by removal of electrons from atoms of the catalyst material. Often, this can be discussed as an increase in the integer number that describes the formal oxidation state of the metal ions. In OER electrocatalyst materials, the 
accumulation of oxidizing equivalents typically is not associated with the accumulation of positive charges because of charge compensation by proton release or other ion fluxes. The charge-neutral accumulation of oxidizing equivalents by metal oxides is essential also for other electrochemical devices, specifically for batteries. ${ }^{29-33}$ Merely for simplicity, we refer, in the following, to the chargeneutral accumulation of oxidizing equivalents also as charging, charge accumulation, or stored charges.

It is crucial for the development of batteries and electrocatalytic devices to understand how charges are stored in the metal oxide structure and how they interact with each other. Experimentally, charge accumulation by the formation of high oxidation states, e.g., formation of $\mathrm{Co}^{4+}$ ions in the oxide matrix, can be probed with $\mathrm{x}$-ray techniques. Using in situ $\mathrm{x}$-ray absorption spectroscopy (XAS), it is possible to track oxidation state changes during OER operation $^{8,10,34-38}$ or during charge/discharge of batteries. ${ }^{39-41}$

Furthermore, structural sensitive spectroscopies such as XAS, $\mathrm{x}$-ray diffraction (XRD), infrared spectroscopy (IR), and Raman spectroscopy are used, in catalytic studies, to determine the structural rearrangements of the oxide lattice. For example, XAS has been used to assign specific structural motifs to oxygen evolving sites detecting di- $\mu$-oxo bridged homonuclear and heteronuclear sites in Co-Fe oxides; ${ }^{11}$ IR-spectroelectrochemistry was essential in discarding a metal-oxo radical as the first intermediate of OER in hematite, detecting, instead, the formation of the $\mathrm{Fe}(\mathrm{IV})-\mathrm{O}$; and Raman spectroscopy identified $\mu$-OO peroxide species involved in OER in $\mathrm{Co}_{3} \mathrm{O}_{4} ;{ }^{42}$ it could also clarify the origin of the relation between $\mathrm{pH}$ and catalytic efficiency in $\mathrm{NiOOH}^{43}$ In batteries, these spectroscopies are used to study local irreversible structure changes during partial charging/discharging. ${ }^{44-46}$

Compared to in situ IR spectroscopy, Raman spectroscopy is gaining popularity in the study of electrochemical devices since it can be easily adapted to in situ or operando measurements. It can easily be employed for investigations of oxide electrodes in various solvents, including aqueous electrolytes. Due to the resonance and/or surface enhancement effects, the sensitivity toward surface species or particular elements can be often tuned. Indeed, operando Raman spectroscopy has been used in battery research to characterize practical electrodes during charging and discharging operations. ${ }^{4}$

Cobalt oxides offer the possibility to compare results obtained in battery and OER research. Co oxides are highly promising for OER catalysis at neutral $\mathrm{pH}$, in the form of amorphous $\mathrm{CoO}_{\mathrm{x}}$. Structurally closely related Co oxides are heavily employed as the cathode material in lithium batteries, as $\mathrm{LiCoO}_{2}$. In cathodes of $\mathrm{Li}$-ion batteries, $\mathrm{LiCoO}_{2}$ is found in a layered oxide structure with edgesharing $\mathrm{CoO}_{6} \cdot{ }^{31,44}$ In the reduced form, the Li cation occupies sites in between of the $\mathrm{CoO}_{2}$ layers. During charging $\left(\mathrm{Co}^{3+/ 4+}\right.$ oxidation), the $\mathrm{Li}$ ion is transferred into the electrolyte medium (e.g., $\mathrm{Li}_{3} \mathrm{PO}_{4}$ formation), thereby forming pure $\mathrm{CoO}_{2}$. These processes have been monitored by Raman spectroscopy, where during oxidation, a shift of the $\mathrm{Co}-\mathrm{O}$ bands to lower frequencies can be detected. ${ }^{44,45}$

The structure of amorphous $\mathrm{CoO}_{\mathrm{x}}$ for OER has been found to be highly dependent on the preparation conditions. ${ }^{47}$ Nevertheless, XAS measurement revealed that, during operation, regardless on the initial composition, $\mathrm{CoO}_{\mathrm{x}}$ converts to a local structure similar to $\mathrm{CoO}_{2}$, e.g., octahedrally coordinated, di- $\mu$-oxo-bridged $\mathrm{Co}^{3+}$ ions, ${ }^{48}$ with a strong structural similarity to $\mathrm{LiCoO}_{2}$ (see Fig. S1).
This catalyst material, herein denoted as CoCat, corresponds to the self-healing CoPi introduced by Kanan and co-workers. ${ }^{21}$ Several OER mechanisms have been proposed for the CoCat, involving, e.g., $\mathrm{O}-\mathrm{O}$ bond formation through two geminal metal-oxo ligands or two vicinal terminal oxygen or via nucleophilic attack of water. ${ }^{48-50}$ Recently, a debate has opened on the mechanistic importance of proton scavenging during OER operation, hence on the ability of the buffer base, to efficiently remove protons from the active site surroundings.

In summary, in Li-ion batteries based on Co oxides and in OER catalysis such as the CoCat, $\mathrm{Co}^{3+/ 4+}$ oxidation state changes are functionally decisive. In both materials, the charging of the material is an oxidative charging that precedes the overall charge-neutral because either $\mathrm{Li}$ ions (in batteries) or protons (in CoCat) leave the electrode material. In both materials, the oxidative charging is not restricted to a specific surface but occurs throughout the catalyst material. For the CoCat, not only the oxidative charging but also OER catalysis takes place throughout the catalyst material, ${ }^{51}$ most likely at the margins of Co-oxo clusters, which constitute the amorphous catalyst (typically less than 20 Co atoms). ${ }^{51,54,55}$ This has been denoted as volume activity, as opposed to catalysis taking place exclusively at the outer catalyst surface, that is, at the catalyst-film-bulk-electrolyte interface.

Here, we use operando Raman spectroscopy to probe the active sites of CoCat during OER operated in phosphate buffer, at neutral $\mathrm{pH}$. After establishing experimental conditions that avoid laserheating artifacts, we assign the various observed bands to molecular groups. The vibrational spectra were studied at various electric potentials in the catalytic and near-catalytic range, inter alia employing isotope labeling of the catalyst material in $\mathrm{D}_{2} \mathrm{O}$ or $\mathrm{H}_{2}{ }^{18} \mathrm{O}$ water. The results are also correlated with those of the previous XAS studies of the same CoCat material, inter alia to propose methods for detecting Co oxidation state changes in the OER catalyst material with Raman spectroscopy. We also compare our CoCat results to previous findings obtained by Raman spectroscopy for $(\mathrm{Li}) \mathrm{CoO}_{2}$ in functional battery electrodes, where Raman band shifts were followed during the charging and discharging process.

\section{RESULTS AND DISCUSSION}

\section{A. Raman spectra of amorphous $\mathrm{CoO}_{x}$}

Raman spectra of an amorphous Co oxide catalyst (CoCat) electrodeposited at $\mathrm{pH} 7$ in $0.1 \mathrm{M} \mathrm{KPi}(\mathrm{KPi}$, potassium phosphate solution) were investigated, aiming at assignment of all bands (peaks) of the Raman spectrum (for experimental details, see the supplementary material). The CoCat was deposited on a Pt substrate electrode because the metallic substrate, with its high thermal conductivity, minimizes heating by the focused laser beam employed in the Raman experiment. Moreover, platinum does not exhibit relevant Raman bands, as opposed to carbon materials, and is largely inactive in OER catalysis. A gold substrate was not used because for the bare $\mathrm{Au}$ electrode, vibrational bands are observable that tend to interfere significantly with the Raman spectra of the CoCat catalyst. ${ }^{56}$ We emphasize that laser-heating artifacts are a serious concern. Transformation of $\mathrm{CoO}$ into $\mathrm{Co}_{3} \mathrm{O}_{4}$ driven by irradiation with the Raman excitation-laser has been previously reported by Rivas-Murias and Salgueiriño, ${ }^{57}$ and we observed a similar 
transformation for CoCat deposited on a glassy-carbon substrate electrode exposed to an alkaline electrolyte (Fig. S2). Such and other irradiation damage effects were avoided in our investigations by the choice of the substrate electrode (metallic $\mathrm{Pt}$ ), reduction of the laser power (typically to about $1 \mathrm{~mW}$ ), and the use of a line focus with estimated dimensions of $\sim 2 \times 50 \mu \mathrm{m}^{2}$ (instead of a point focus of $2 \mu \mathrm{m}$ diameter), thereby reducing the laser-light intensity (per area).

A typical Raman spectrum for CoCat electrodes exposed to an electrolyte is composed of two contributions: the electrolyte spectrum and the spectrum of the CoCat film itself (Fig. 1), which is
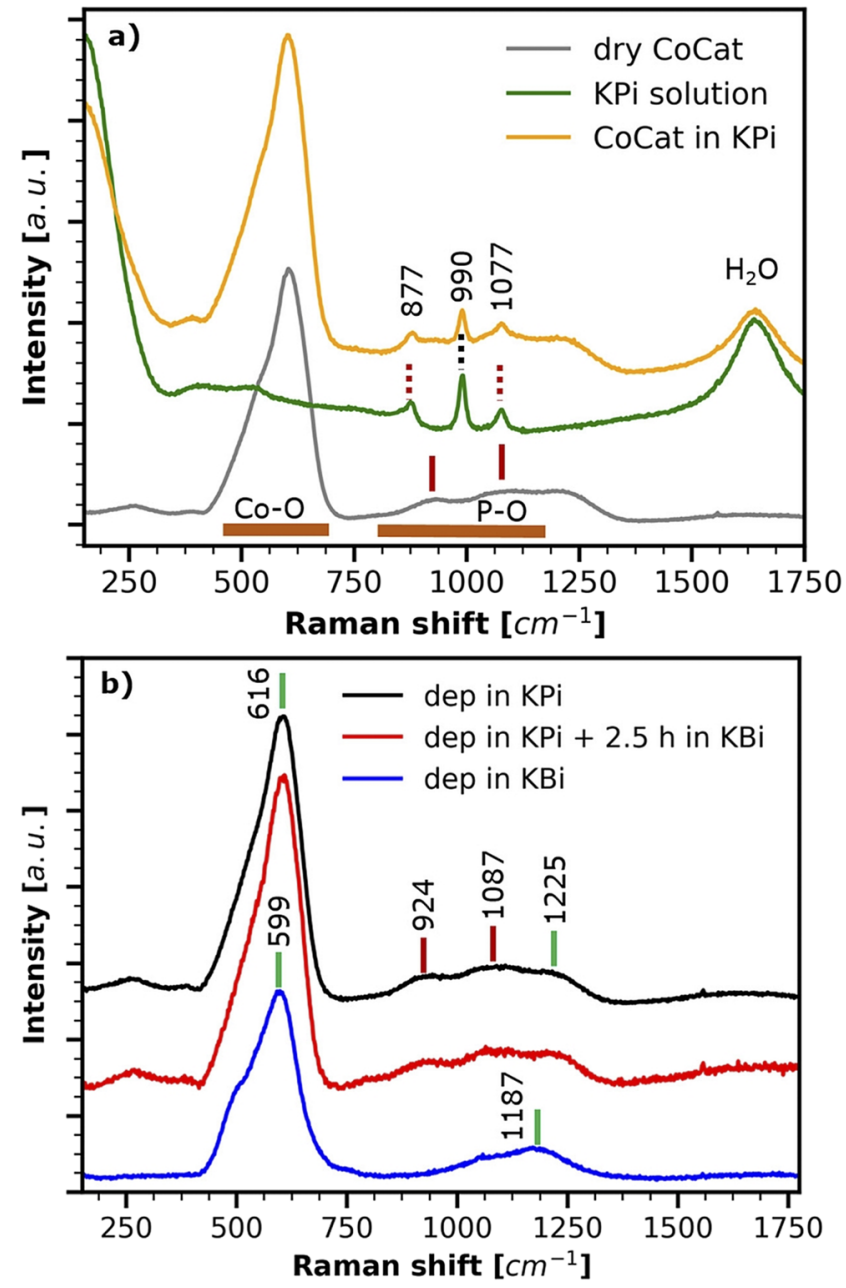

FIG. 1. CoCat Raman spectra. The CoCat deposition charge is $300 \mathrm{mC} \mathrm{cm}^{-2}$, which corresponds to $\sim 3 \mu \mathrm{mol}$ Co per $\mathrm{cm}^{-2}$ (deposited on Pt). (a) Dried CoCat sample (bottom spectrum), $0.1 \mathrm{M} \mathrm{KPi}$ solution (intermediate spectrum) at $\mathrm{pH} 7$, and CoCat in the solution (top spectrum). (b) Dried CoCat sample deposited either in $0.1 \mathrm{M} \mathrm{KPi}$ at pH 7 (top spectrum) or in $0.1 \mathrm{M} \mathrm{KBi}$ (potassium borate) at pH 9.2 (bottom spectrum) and CoCat deposited in $0.1 \mathrm{M} \mathrm{KPi}$ and then exposed to $0.1 \mathrm{M}$ $\mathrm{KBi}$ (intermediate spectrum). Short vertical lines are used to indicate the peaks' position: solid lines correspond to CoCat peaks, dotted lines to solution peaks, green color to $\mathrm{Co}-\mathrm{O}$ vibrations, red color to $\mathrm{H}_{2} \mathrm{PO}_{4}{ }^{-}$vibrations, and black color to $\mathrm{HPO}_{4}{ }^{2-}$ vibrations. characterized by very broad bands. The presence of broad bands is typical for amorphous compounds because the lack of order and presence of defects broaden the distribution of bond strengths and angles, thus modulating the vibrational frequencies and resulting in broad vibrational bands. ${ }^{55}$ These broad bands are usually simulated using Gaussian functions, which represent the sum of Lorentzian functions with a broad distribution of vibrational frequencies. In the spectral range shown in Fig. 1, the electrolyte $(0.1 \mathrm{M} \mathrm{KPi}$ in water) exhibits a water band at $1641 \mathrm{~cm}^{-1}(\mathrm{H}-\mathrm{O}-\mathrm{H} \text { bending })^{58}$ and three comparably sharp bands stemming from the phosphate species in the aqueous solution [dotted lines in Fig. 1(a)]: at $877 \mathrm{~cm}^{-1}$ and $1077 \mathrm{~cm}^{-1}$ from $\mathrm{H}_{2} \mathrm{PO}_{4}{ }^{-}$and at $990 \mathrm{~cm}^{-1}$ from $\mathrm{HPO}_{4}{ }^{2-}{ }^{-59}$ In operando studies, these bands can provide insight into the local $\mathrm{pH}$ close to the macroscopic electrode surface. ${ }^{60,61}$

The spectra of the dry CoCat have three very broad bands (924 $\mathrm{cm}^{-1}, 1087 \mathrm{~cm}^{-1}$, and $1225 \mathrm{~cm}^{-1}$ ) in the same region as the vibration of phosphate species in the solution. Substituting phosphate for arsenate, $\mathrm{x}$-ray absorption spectroscopy at the As K-edge, recently, has provided support for phosphate binding at the margins of Co oxide fragments. ${ }^{62}$ A possible hypothesis is that the $877 \mathrm{~cm}^{-1}$ and $1077 \mathrm{~cm}^{-1}$ solution peaks from $\mathrm{H}_{2} \mathrm{PO}_{4}^{-}$[indicated by dotted red lines in Fig. 1(a)] are broadened and shifted to $924 \mathrm{~cm}^{-1}$ and $1087 \mathrm{~cm}^{-1}$ (solid red lines) when phosphate is trapped in between the Co-oxo clusters. A broadening and shifting in the same direction is observed when the phosphate concentration in the solution is increased. ${ }^{63}$ This change can be explained with the formation of phosphate dimers or polymers, which share an oxygen atom, since phosphate polymerization is a reaction close to equilibrium. ${ }^{64}$ The polyphosphates, which likely surround the Co-oxo clusters, can form a hydrogen-bond network, which likely favors proton transport inside the catalyst material. ${ }^{63,65,66}$ On the contrary, the $990 \mathrm{~cm}^{-1}$ solution-peak (dotted black line) has no visible correspondence in the dry-CoCat spectrum, suggesting that phosphate is present inside the CoCat film mainly in the $\mathrm{H}_{2} \mathrm{PO}_{4}{ }^{-}$form.

To test the assignment of these bands to phosphate, we changed the deposition solution from $\mathrm{KPi}$ to $\mathrm{KBi}$ buffer at $\mathrm{pH}$ 9.2. A more evident shoulder for the main Co-oxo peak and a large band at $1187 \mathrm{~cm}^{-1}$ with a left shoulder appeared in the Raman spectra [Fig. 1(b)]. At the same time, the $924 \mathrm{~cm}^{-1}$ and $1087 \mathrm{~cm}^{-1}$ bands disappear, supporting their assignment to $\mathrm{H}_{2} \mathrm{PO}_{4}{ }^{-}$. The $1187 \mathrm{~cm}^{-1}$ band is suggested to be the two-phonon scattering corresponding to double frequency of the $599 \mathrm{~cm}^{-1}$ one-phonon scattering. Similarly, in KPi deposited CoCat, the $1225 \mathrm{~cm}^{-1}$ would be the two-phonon scattering corresponding to the $616 \mathrm{~cm}^{-1}$ one-phonon scattering; all $\mathrm{Co}-\mathrm{O}$ vibrations are indicated by solid green lines in Fig. 1(b). A two-phonon scattering peak has been previously reported for $\mathrm{CoO}$ at $1060 \mathrm{~cm}^{-1}$.

When the sample deposited in $\mathrm{KPi}$ is exposed to a KBi solution for $2.5 \mathrm{~h}$, even while applying a potential, no change appears in the CoCat spectrum [Fig. 1(b) and Fig. S3]. This result confirms that exchange of phosphate in CoCat is very slow. ${ }^{68}$

In the region typical for $\mathrm{M}-\mathrm{O}$ vibrations, the CoCat has a peak at $615 \mathrm{~cm}^{-1}$ with a shoulder at $544 \mathrm{~cm}^{-1}$, in agreement with the spectra reported in the literature. ${ }^{55,69}$ These two bands have been assigned, respectively, to $\mathrm{Co}-\mathrm{O}$ vibrations $\left(\mathrm{A}_{1 \mathrm{~g}}, 595 \mathrm{~cm}^{-1}\right)$ and $\mathrm{Co}-\mathrm{O}-\mathrm{Co}$ vibrations $\left(\mathrm{E}_{\mathrm{g}}, 485 \mathrm{~cm}^{-1}\right)$ in a $\mathrm{CoO}_{6}$ octahedron in the $\mathrm{LiCoO}_{2}$ structure ${ }^{55,70}$ and are present at similar frequencies in $\mathrm{CoO}(\mathrm{OH}){ }^{71}$ The shoulder is more evident when CoCat is deposited 
in $\mathrm{KBi}$ [Fig. 1(b)], coherent with the supposed presence of more $\mathrm{Co}-\mathrm{O}-\mathrm{Co}$ bond in the more ordered structure. ${ }^{5}$

The IR spectrum of CoCat was collected using an attenuated total reflection (ATR) mode and presents two main broad bands (Fig. S4). Each IR band corresponds to a Raman band: a Co-O band in the $450-500 \mathrm{~cm}^{-1}$ region and a $\mathrm{P}-\mathrm{O}$ band in the $800-1200 \mathrm{~cm}^{-1}$ region. Unlike for the Raman spectra, these bands strongly depend on the thickness of the CoCat sample and are blue-shifted and broadened in thicker samples.

In summary, the study of the dry CoCat Raman spectrum revealed the presence of two $\mathrm{Co}-\mathrm{O}$ vibrations' peaks, with a corresponding two-phonon peak, and of two phosphate peaks. The presence of the corresponding bands in the IR spectrum suggests that these vibrations are both Raman and IR active. The broad main $\mathrm{Co}-\mathrm{O}$ peak likely is dominated by $\mathrm{Co}-\mathrm{O}$ stretching vibrations from both bridging and terminal oxygen atoms, whereas the shoulder at a lower wave number is more closely related to $\mathrm{Co}-\mathrm{O}-\mathrm{Co}$ vibrations associated with $\mu$-oxo bridging between Co ions. Consequently, the amplitude ratio could shift in favor of the long-wavelength shoulder upon increased $\mu$-oxo bridging, as is observed, here, for a sample electrodeposited in KBi electrolyte. The phosphate bands can be assigned to phosphate trapped inside the material, mainly in the form of highly concentrated $\mathrm{H}_{2} \mathrm{PO}_{4}{ }^{-}$surrounding the Co-oxo clusters. At these concentrations, phosphate starts forming dimers or polymers forming a hydrogen-bond network, which, in the CoCat, can be functional for proton transport. ${ }^{63,65,66}$

\section{B. Spectral changes with applied potential}

The identification of catalytic intermediates in CoCat may be facilitated by the use of operando Raman spectroscopy. We used a Raman spectrometer equipped with a water immersion objective and a three electrodes cell (Fig. S5) to investigate the modification of the Raman spectrum driven by an applied potential. The potential was increased in small steps ("potential stair" protocol, details in the methods section), and the Raman spectrum was measured at each potential after reaching a stable state (i.e., after $2 \mathrm{~min}$ ). Spectra are shown in Fig. 2(a), and for thinner films, Fig. S6, peak positions and amplitudes are listed in Table I (other parameters in Table S I and an example of the simulation in Fig. S7); potentials are reported in the NHE (normal hydrogen electrode) scale.

The above mentioned changes in the Raman spectrum driven by application of an electric potential are completely reversible [Fig. 2(b)] and consists in a shift to lower energies of the main $\mathrm{Co}-\mathrm{O}$ peak and its shoulder, with the shoulder becoming more prominent, and a gradual disappearance of the two-phonon band at $1225 \mathrm{~cm}^{-1}$ [Fig. 2(c)]. The relative increase in the shoulder intensity is likely due to the formation of additional $\mu$-oxo bridges at higher potentials. Since the main $616 \mathrm{~cm}^{-1}$ band decreases with the potential, the corresponding two-phonon process (at $1225 \mathrm{~cm}^{-1}$ ), which involves a three-particle interaction, is expected to decrease even faster, as it is observed. The $924 \mathrm{~cm}^{-1}$ and $1087 \mathrm{~cm}^{-1}$ bands are not depending significantly on potential (see Table I), confirming the assignment to $\mathrm{H}_{2} \mathrm{PO}_{4}{ }^{-}$vibrations.

At high potentials, there are no new bands appearing in the $900-1200 \mathrm{~cm}^{-1}$ region. A series of $\mathrm{O}-\mathrm{O}$ peaks were reported in this region when positive potentials were applied in the alkaline electrolyte, for example, peaks from $\mu$-OO peroxide in $\mathrm{Co}_{3} \mathrm{O}_{4}$ (Ref. 42),
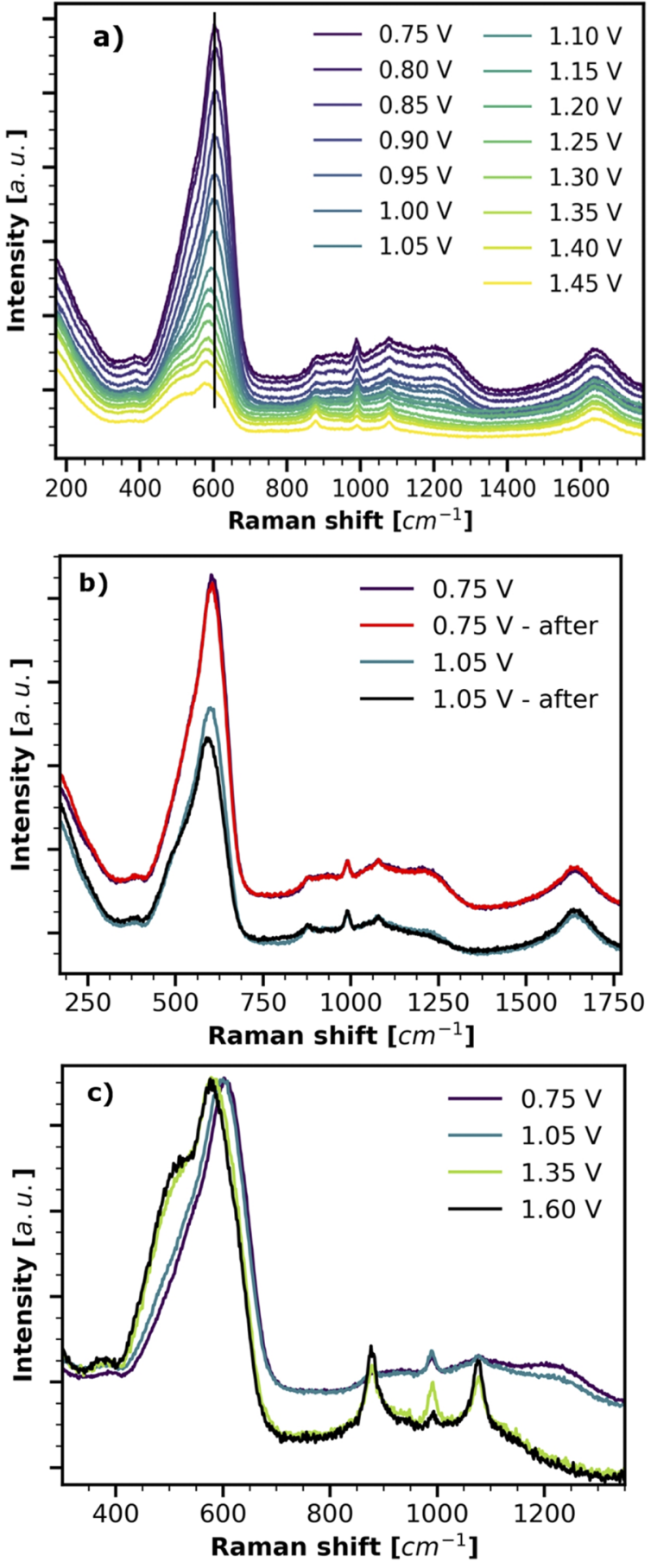

FIG. 2. Raman spectra for CoCat collected at various potentials in $0.1 \mathrm{M} \mathrm{KPi}$ at $\mathrm{pH}$ 7. The deposition charge is $40 \mathrm{mC} \mathrm{cm}$-2 on the Pt substrate. (a) Raman spectra during a potential-stair experiment. Few outlier spectra were rescaled for clarity purposes. (b) Raman spectra collected at selected potentials during the "potential stair" experiment and directly after it. Directly after the "potential stair" experiment, the potential was lowered again (spectra denoted by "after"), to control the reversibility of the observed changes. (c) Selected spectra were rescaled to enhance differences in shape and position. 
TABLE I. Amplitudes and positions of the major Raman peaks (in counts and $\mathrm{cm}^{-1}$, respectively) for CoCat operated at different potentials. Each peak was simulated with a Gaussian function. X indicates peaks with near-zero amplitude. Typical errors (confidence intervals) are reported in the last row (in percent of the peak-amplitude values and in $\mathrm{cm}^{-1}$ for the peak positions). An example illustrating the simulation approach and quality is shown in Fig. S7; all simulation parameters are shown in Table S I.

\begin{tabular}{|c|c|c|c|c|c|c|c|c|c|c|}
\hline & \multicolumn{2}{|c|}{$\mathrm{Co}-\mathrm{O}-\mathrm{Co}$} & \multicolumn{2}{|c|}{$\mathrm{Co}-\mathrm{O}$} & \multicolumn{2}{|c|}{$\mathrm{H}_{2} \mathrm{PO}_{4}^{-}$} & \multicolumn{2}{|c|}{$\mathrm{H}_{2} \mathrm{PO}_{4}^{-}$} & \multicolumn{2}{|c|}{$2^{*} \mathrm{Co}-\mathrm{O}$} \\
\hline & Ampl. & Pos. & Ampl. & Pos. & Ampl. & Pos. & Ampl. & Pos. & Ampl. & Pos. \\
\hline $0.75 \mathrm{~V}$ & 3550 & 550 & 5242 & 614.8 & 532 & 925 & 850 & 1077 & 782 & 1220 \\
\hline $0.80 \mathrm{~V}$ & 4411 & 551 & 6418 & 615.2 & 551 & 927 & 1008 & 1081 & 895 & 1224 \\
\hline $0.85 \mathrm{~V}$ & 3944 & 551 & 5720 & 615.1 & 461 & 924 & 890 & 1083 & 734 & 1228 \\
\hline $0.90 \mathrm{~V}$ & 3436 & 549 & 5081 & 614.5 & 390 & 926 & 781 & 1082 & 633 & 1228 \\
\hline $0.95 \mathrm{~V}$ & 2746 & 548 & 4128 & 614.1 & 352 & 928 & 640 & 1077 & 542 & 1222 \\
\hline $1.00 \mathrm{~V}$ & 2416 & 543 & 3773 & 611.9 & 287 & 932 & 574 & 1080 & 418 & 1226 \\
\hline $1.05 \mathrm{~V}$ & 2606 & 534 & 4448 & 608.4 & 375 & 921 & 653 & 1083 & 373 & 1228 \\
\hline $1.10 \mathrm{~V}$ & 1416 & 517 & 2962 & 602.3 & 229 & 932 & 378 & 1080 & 200 & 1216 \\
\hline $1.15 \mathrm{~V}$ & 970 & 507 & 2182 & 596.5 & 132 & 932 & 247 & 1080 & 73 & 1224 \\
\hline $1.20 \mathrm{~V}$ & 1256 & 504 & 2632 & 594.1 & 176 & 915 & 298 & 1078 & 41 & 1228 \\
\hline $1.25 \mathrm{~V}$ & 1187 & 504 & 2266 & 593.5 & 172 & 910 & 267 & 1074 & 25 & 1232 \\
\hline $1.30 \mathrm{~V}$ & 1063 & 503 & 1911 & 592.9 & 177 & 903 & 226 & 1070 & 9 & 1229 \\
\hline $1.35 \mathrm{~V}$ & 963 & 502 & 1696 & 591.5 & 190 & 898 & 220 & 1073 & 6 & 1220 \\
\hline $1.40 \mathrm{~V}$ & 877 & 502 & 1472 & 591.4 & 162 & 903 & 196 & 1075 & $\mathrm{X}$ & $X$ \\
\hline $1.45 \mathrm{~V}$ & 675 & 501 & 1115 & 590.7 & 119 & 898 & 158 & 1072 & $\mathrm{X}$ & $\mathrm{X}$ \\
\hline Error (\%) & 2 & 2 & 2 & 0.5 & 10 & 5 & 2 & 5 & 10 & 5 \\
\hline
\end{tabular}

$\mathrm{IrO}_{2}$ (Ref. 72) and from $\mathrm{NiOx}$ superoxide ${ }^{73}$ and peroxide, ${ }^{74}$ even though the Ni bands are also compatible with a two-phonon Raman bands. The absence of such peaks in the spectra recorded for CoCat at neutral $\mathrm{pH}$ suggests that special oxygen species, e.g., terminal oxides $(\mathrm{Co}=\mathrm{O})$ or bound peroxides, are not long-lived intermediates in the OER reaction that accumulate at a detectable level (see the supplementary material for discussion of the detection limit). The absence of peroxide species is consistent with the reaction mechanism proposed for CoCat, ${ }^{9,10,27,75,76}$ where the $\mathrm{O}-\mathrm{O}$ bond formation is rate-limiting, and thus, it is not observable in a stable state. It remains unclear why at high potentials Raman bands potentially assignable to terminal oxides are not detected.

The behavior of the Co-O Raman peaks following application of a potential is in line with the proposed peak assignment and excludes the formation of a major fraction of a long-lived peroxide intermediate. The change in signal intensity and the red-shift of the two main $\mathrm{Co}-\mathrm{O}$ peaks with potential are further investigated in Secs. II D and II E, while Sec. II C is dedicated to isotopic substitution.

\section{C. $\mathrm{H} / \mathrm{D}$ and ${ }^{16} \mathrm{O} /{ }^{18} \mathrm{O}$ isotope effect}

Isotopic substitution is often used in vibrational spectroscopy for band assignment and, when coupled with an applied potential, can provide insights into the reaction mechanism. We investigated the modification of the Raman spectrum caused by deuterated water $\left({ }^{2} \mathrm{H}^{16} \mathrm{O}\right.$ isotope $)$ and ${ }^{18} \mathrm{O}$ water $\left({ }^{1} \mathrm{H}_{2}{ }^{18} \mathrm{O}\right)$ electrolytes.

In deuterated water, shifts for the water and phosphate peaks are clearly visible [Figs. 3(a) and 3(c)]; these peaks are moving to $1207 \mathrm{~cm}^{-1}, 862 \mathrm{~cm}^{-1}, 988 \mathrm{~cm}^{-1}$, and $1085 \mathrm{~cm}^{-1}$, respectively, and so are the peaks in the $3000-3500 \mathrm{~cm}^{-1}$ region (Fig. S8). The shift of the Co-O bands is comparatively minor [Fig. 3(d)]. Band positions were determined by simulation with Gaussian functions and are presented in Table II, the simulation parameters in Table S II, and an example of the simulation in Fig. S7.

The first two peaks, corresponding to $\mathrm{Co}-\mathrm{O}$ vibrations, are both red-shifted in $\mathrm{D}_{2} \mathrm{O}$ by about $5 \mathrm{~cm}^{-1}$, and the shift is clearly less pronounced at high potentials. The isotope shift suggests that (i) the catalyst film harbors a significant number of protonated oxygen, both as bridging $(\mathrm{Co}-\mathrm{OH}-\mathrm{Co})$ and terminal $(\mathrm{Co}-\mathrm{OH}$ and $\mathrm{Co}-\mathrm{OH}_{2}$ ) ligands at low potentials and (ii) deprotonation happens at increased potential. Deprotonation of bridging or terminal oxygen atoms accompanies Co oxidation (proton-coupled electron transfer) and avoids charge buildup, ${ }^{77-79}$ similarly to $\mathrm{Li}^{+}$release coupled to Co oxidation in battery materials. ${ }^{80}$ The deprotonation of $\mu$-oxo bridges at high potentials has been proposed before, based on XAS data, ${ }^{10}$ but we provide the first direct experimental evidence here.

For measurements in ${ }^{18} \mathrm{O}$ water, the sample was conditioned in an ${ }^{18} \mathrm{O}$ electrolyte by exposure of the CoCat to ${ }^{18} \mathrm{O}$ water for $30 \mathrm{~min}$ at OCP (open circuit potential) followed by a cyclic voltammetry (CV) scan $\left(0.8-1.3 \mathrm{~V}_{\mathrm{NHE}}\right.$ with a scan rate of $\left.1 \mathrm{mV} \mathrm{s}^{-1}\right)$. This procedure has been shown to promote the exchange of all ${ }^{16} \mathrm{O}$ atoms that are involved in $\mathrm{O}-\mathrm{O}$ bond formation resulting in $\mathrm{O}_{2}$ release. ${ }^{68}$ Spectra obtained in the ${ }^{18} \mathrm{O}$ electrolyte show no major differences from those obtained in the ${ }^{16} \mathrm{O}$ electrolyte [Figs. 3(b) and 3(e)]. The simulation of the bands' position reveals that, at intermediate and high potentials, the main $\mathrm{Co}-\mathrm{O}$ peak is red-shifted by $\sim 2-3 \mathrm{~cm}^{-1}$ in the ${ }^{18} \mathrm{O}$ electrolyte [Fig. 3(f) and Table II], while the shoulder corresponding to $\mathrm{Co}-\mathrm{O}-\mathrm{Co}$ vibrations is not shifted. 

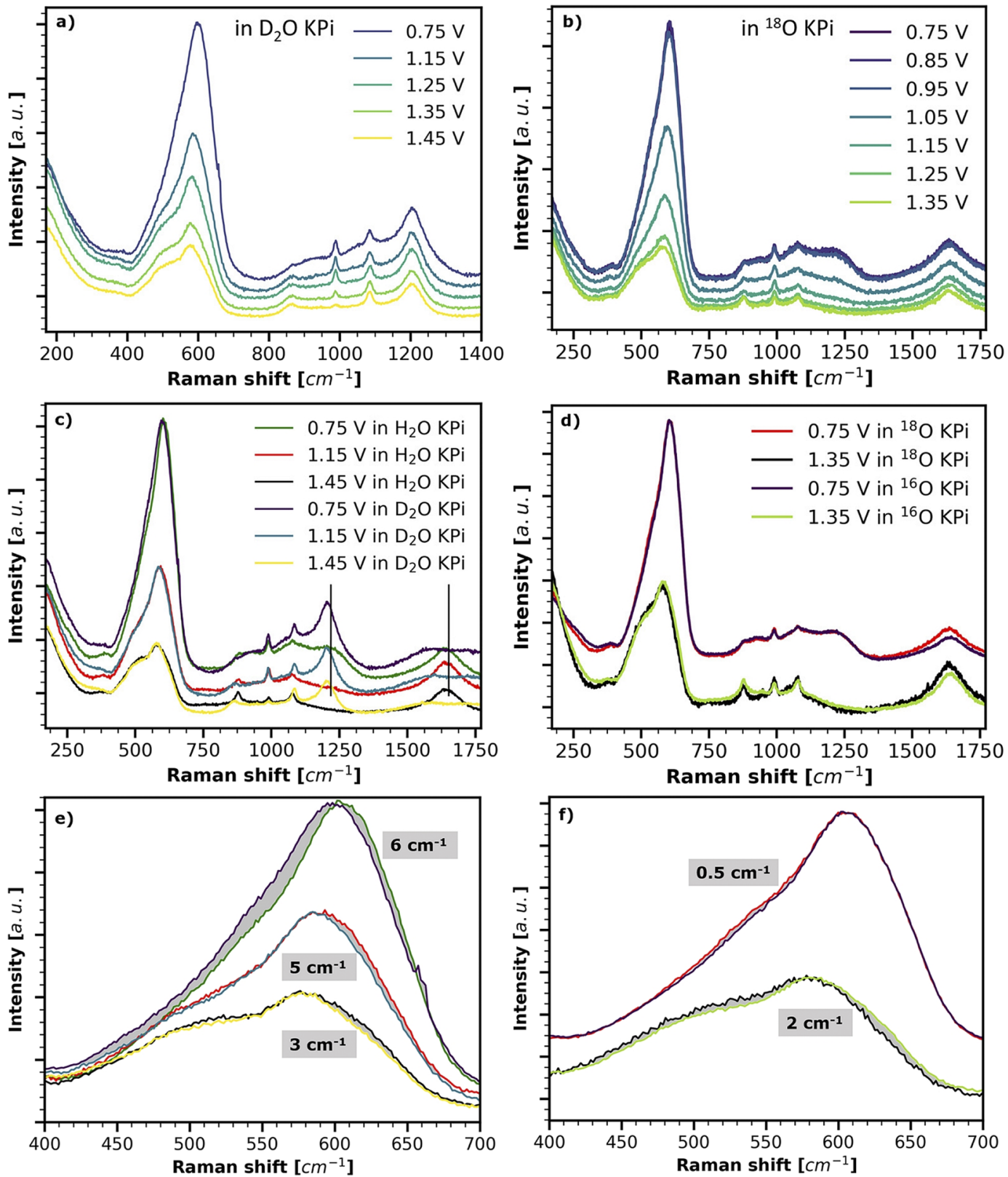

FIG. 3. Raman spectra for CoCat operated at the indicated potentials (vs NHE, in $0.1 \mathrm{M} \mathrm{KPi}$ at pH 7), in deuterated water $\left({ }^{2} \mathrm{H}_{2}{ }^{16} \mathrm{O}\right.$ isotope) or ${ }^{18} \mathrm{O}$ water $\left({ }^{1} \mathrm{H}_{2}{ }^{18} \mathrm{O}\right.$ isotope). (a) $\mathrm{D}_{2} \mathrm{O}$ spectra and (c) $\mathrm{D}_{2} \mathrm{O}$ with $\mathrm{H}_{2} \mathrm{O}$ rescaled spectra for comparison. (b) $\mathrm{H}_{2}{ }^{18} \mathrm{O}$ spectra and (d) $\mathrm{H}_{2}{ }^{16} \mathrm{O}$ with $\mathrm{H}_{2}{ }^{18} \mathrm{O}$ rescaled spectra for comparison. In (e) and (f), the spectral region corresponding to $\mathrm{Co}-\mathrm{O}$ vibrations is expanded to emphasize the differences (gray area) between the $\mathrm{D}_{2} \mathrm{O}$ spectra and $\mathrm{H}_{2} \mathrm{O}$ spectra [in (e)] and $\mathrm{H}_{2}{ }^{16} \mathrm{O}$ with $\mathrm{H}_{2}{ }^{18} \mathrm{O}$ spectra [in (f)]. The numerical value of the shift is calculated from the peak positions, reported in Table II. The CoCat film has been deposited on a Pt substrate electrode with

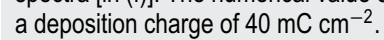

For an isolated Co-O bond, an ${ }^{18} \mathrm{O}$ isotopic shift of $7 \mathrm{~cm}^{-1}$ is expected and experimental observation of $\mathrm{Ir}=\mathrm{O}$ revealed a $59 \mathrm{~cm}^{-1}$ isotopic shift. ${ }^{81}$ The small shift that we observed can be attributed to the incomplete or missing exchange of the oxygen in the $\mu$-oxo bridges $(\mathrm{Co}-\mathrm{O}-\mathrm{Co})$, confirming that they do not take part in the OER process. ${ }^{68}$
Thus, the majority of oxygen atoms is not exchangeable (no ${ }^{18} \mathrm{O}$ incorporation), even for operation at catalytic potentials. The CoCat has been proposed to consist of comparably small fragments of a layered oxide (less than 20 Co ions) with internal oxygens bridging between three Co ions $\left(\mu_{3}-\mathrm{O}\right)$ and peripheral oxygens found in the form of $\mu_{2}-\mathrm{O}$ bridges and terminally coordinated oxygen 
TABLE II. Positions of the major Raman peaks (in $\mathrm{cm}^{-1}$ ) for CoCat operated at different potentials in water, deuterated water or ${ }^{18} \mathrm{O}$ water. Each peak was simulated with a Gaussian function; Lorentzian functions were also tested but performed worse. Parenthesis indicates peaks that are uncertain due to significant spectral overlap with Raman bands from phosphate species in the electrolyte; $\mathrm{X}$ indicates peaks with near-zero amplitude, which were not included in the simulation. An example illustrating the simulation approach and quality is shown in Fig. S7; all simulation parameters are shown in Table S II.

\begin{tabular}{ccccccc}
\hline \hline & & $\mathrm{Co}-\mathrm{O}-\mathrm{Co}$ & $\mathrm{Co}-\mathrm{O}$ & $\mathrm{H}_{2} \mathrm{PO}_{4}{ }^{-}$ & $\mathrm{H}_{2} \mathrm{PO}_{4}{ }^{-}$ & $2^{*} \mathrm{Co}-\mathrm{O}$ \\
\hline \multirow{3}{*}{$0.75 \mathrm{~V}$} & $\mathrm{H}_{2}{ }^{16} \mathrm{O}$ & $552.3 \pm 2.2$ & $615.6 \pm 0.2$ & $930 \pm 6$ & $1083 \pm 5$ & $1227 \pm 6$ \\
& $\mathrm{D}_{2}{ }^{16} \mathrm{O}$ & $547.6 \pm 6.4$ & $609.7 \pm 0.4$ & $926 \pm 4$ & $1071 \pm 5$ & $(1207 \pm 5)$ \\
& $\mathrm{H}_{2}{ }^{18} \mathrm{O}$ & $551.4 \pm 1.9$ & $615.9 \pm 0.2$ & $926 \pm 4$ & $1082 \pm 5$ & $1226 \pm 5$ \\
\hline & $\mathrm{H}_{2}{ }^{16} \mathrm{O}$ & $506.3 \pm 0.7$ & $596.9 \pm 0.3$ & $933 \pm 8$ & $1078 \pm 3$ & $1226 \pm 8$ \\
$1.15 \mathrm{~V}$ & $\mathrm{D}_{2}{ }^{16} \mathrm{O}$ & $500.1 \pm 0.8$ & $592.4 \pm 0.3$ & $933 \pm 10$ & $1082 \pm 6$ & $(1207 \pm 2)$ \\
& $\mathrm{H}_{2}{ }^{18} \mathrm{O}$ & $505.4 \pm 1.0$ & $593.9 \pm 0.4$ & $942 \pm 14$ & $1078 \pm 9$ & $1219 \pm 15$ \\
\hline & $\mathrm{H}_{2}{ }^{16} \mathrm{O}$ & $499.9 \pm 0.7$ & $591.0 \pm 0.5$ & $(912 \pm 4)$ & $(1074 \pm 3)$ & $\mathrm{X}$ \\
$1.35 \mathrm{~V}$ & $\mathrm{D}_{2}{ }^{16} \mathrm{O}$ & $498.0 \pm 0.8$ & $587.6 \pm 0.5$ & $(927 \pm 5)$ & $(1108 \pm 4)$ & $\mathrm{X}$ \\
& $\mathrm{H}_{2}{ }^{18} \mathrm{O}$ & $501.7 \pm 1.2$ & $589.0 \pm 0.7$ & $(944 \pm 3)$ & $(1057 \pm 3)$ & $\mathrm{X}$ \\
\hline \hline
\end{tabular}

atoms $\left(\mathrm{Co}-\mathrm{OH}_{2}, \mathrm{Co}-\mathrm{OH}, \mathrm{Co}=\mathrm{O}\right) .^{34,54,82}$ The minority fraction of exchangeable Co-bound ${ }^{16} \mathrm{O}$ most likely can be found as terminally coordinated oxygen at the periphery of the oxide sheets, as the exchange of bridging oxygen atoms is expected to be especially slow. Previously, participation of bridging oxygen atoms, denoted as "lattice oxygen," to OER has been reported, e.g., for perovskites with high covalency of the metal-oxygen bonds. ${ }^{83}$ The case of CoCat is different because, even though oxygen atoms from the bulk of the material are involved in OER, ${ }^{68}$ those are most likely not "lattice oxygens," but rather may be classified as "surface species" (i.e., terminally coordinated oxygen) that are present in the volume of the material, thanks to its specific amorphous structure.

In summary, the isotopic $\mathrm{H} / \mathrm{D}$ substitution suggests that, likely, (i) a major fraction of both terminal and bridging oxygen atoms are protonated at low potentials and (ii) the number of protonated oxygen atoms is significantly reduced at higher potentials, in line with proton-coupled electron transfer in oxidation/reduction of Co ions. Furthermore, the non-exchangeable oxygen atoms either do not take part in the catalytic reactions or they contribute only indirectly, meaning that they do not leave the catalyst in the form of molecular oxygen.

\section{Raman intensity dependence on Co oxidation state}

In Fig. 4(a), Raman spectra of the CoCat film at various potentials are shown without rescaling or background subtraction. Both the level of the Raman background and the intensity of the CoCat peaks continuously decrease with an increase in the potentials, similarly to what was observed in battery materials. ${ }^{45,84}$ However, part of the trend, at potentials higher than $1.25 \mathrm{~V}_{\mathrm{NHE}}$, may be due to the presence of bubbles in the solution, which decrease the Raman signal intensity.

The presence of a resonance enhancement effect was investigated for CoCat by measuring the Raman spectrum for excitation with three different laser wavelengths $(473 \mathrm{~nm}, 532 \mathrm{~nm}$, and
$633 \mathrm{~nm}$ ). After rescaling the Raman signal by the laser power, no major differences were found in intensity and shape of the three spectra (Fig. S9). The absence of a specific resonance enhancement effect is in line with the very broad absorption bands of CoCat, ${ }^{27}$ and it is conceivable that all spectral bands benefit almost equally from a resonance enhancement effect.

The observed decrease in the magnitude of the Raman bands for increasingly positive potential [Fig. 4(c), Table S II, and Fig. S7] is unexpected because CoCat, as many others transition metal oxides, is an electrochromic material. Electrochromic materials change their absorption spectrum with the applied potential. ${ }^{11,27,85,86}$ In the case of CoCat, the absorption increases with an increase in potential, ${ }^{10,27}$ so that an increase of the Raman resonance enhancement factor is expected at higher potentials. This increase is, indeed, observed for Ni oxides, ${ }^{73}$ whereas we observe a decrease for the CoCat here. An increase in the Raman background for increasingly positive potential was reported for $\mathrm{Cu}$ surface oxides, ${ }^{87}$ which presumably relates to specific surface plasmon effects ${ }^{88}$ that are likely irrelevant for the CoCat Raman signals.

The level of the broad background of the Raman signal is shown on the right axis of Fig. 4(b), in comparison with the change in the Co oxidation state with potential (left axis). The change in the Co oxidation state was obtained by $\mathrm{x}$-ray absorption measurements, as explained in Ref. 27 The UV/Vis absorption at $600 \mathrm{~nm}$ also increases with potential (as expected for electrochromic materials) and perfectly follows the increase in the oxidation state (see Ref. 27 for details on data acquisition for XAS and UV/Vis data). From the comparison of the different datasets emerges the fact that the Raman background intensity has an inverse (notice the inverted axis) dependence on the Co oxidation state and on the Co absorption coefficient.

A possible explanation for the observed behavior is that the $\mathrm{Pt}$ background (Fig. S10) decreases with the increase in the Co oxidation state because Co absorption quenches the background signal due to the increase in its absorption coefficient. The same rationale and a self-absorption phenomenon can explain the decrease in the 

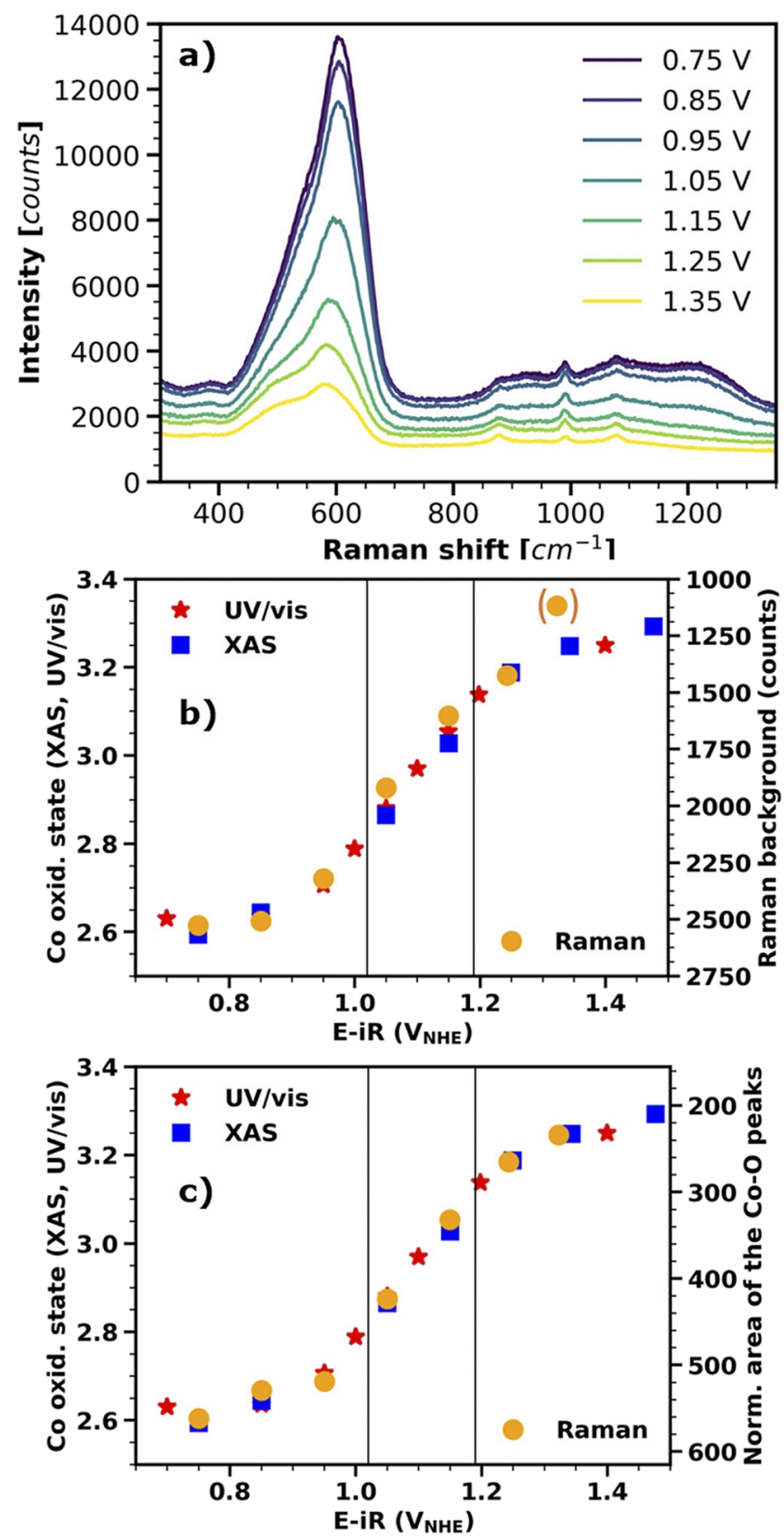

FIG. 4. Dependency of the Raman signal intensity of CoCat on the applied potential (a deposition charge of $40 \mathrm{mC} \mathrm{cm}^{-2}$, Pt substrate, in $0.1 \mathrm{M} \mathrm{KPi}$ at pH 7). (a) Raw (not rescaled) Raman spectra at different applied potentials. (b) Raman-spectra background intensity (right axis, notice the inverted axis) and (c) normalized area of the Co-O Raman peaks (right axis, notice the inverted axis) compared with the Co oxidation state obtained from $x$-ray and UV/Vis absorption measurements (left axis). The background intensity refers to the average of the Raman counts measured between $735 \mathrm{~cm}^{-1}$ and $805 \mathrm{~cm}^{-1}$. The peak area was calculated from a fit of the Co-O peak in the $415-712 \mathrm{~cm}^{-1}$ range (details are given in Table $\mathrm{S}$ II and Fig. S7), after subtraction of a linear background, and was normalized by the background intensity. The parentheses in (b) indicate the data point possibly affected by the presence of bubbles in the solution. The UV/Vis absorption data were rescaled to match the $\mathrm{x}$-ray data. The x-ray and UVNis data are adapted from Ref. 27.
$\mathrm{Co}-\mathrm{O}$ band. This explanation is supported by the analysis of a thin CoCat film (deposition charge of $10 \mathrm{mC}$ instead of $40 \mathrm{mC} \mathrm{cm}{ }^{-2}$ ), which shows a strongly reduced dependence on the applied potential (Figs. S11 and S6b).

$\mathrm{CoO}_{\mathrm{x}}$ represents an anomaly among electrochromic materials because both the level of the Raman background and the intensity of the $\mathrm{Co}-\mathrm{O}$ band have an inverse dependence on the Co oxidation state and absorption coefficient. Like the background intensity, potential-dependent Raman band intensities could also be related to a self-absorption phenomenon, arising from the very broad visibleabsorption band of Co, which have an increased absorption coefficient at high potentials. In any event, the observed dependence provides a method to qualitatively trace changes in the Co oxidation state by Raman spectroscopy.

\section{E. Spectral shape dependence on the Co oxidation state}

In Sec. II D, a red-shift of the $\mathrm{Co}-\mathrm{O}$ peaks with potential was observed, suggesting that the broad $\mathrm{Co}-\mathrm{O}$ band reflects the changes in the Co oxidation state. We test this hypothesis by comparing the change in the Raman peak with the oxidation state of Co as previously estimated based on XAS measurements.

When an increasingly positive potential is applied and Co ions are increasingly oxidized, the $\mathrm{Co}-\mathrm{O}$ bond gets stronger and any pure stretching vibration would be expected to exhibit a blue-shift. Therefore, the observed red-shift suggests that the Co-O vibration is linked to bending modes and not pure stretching vibration. Also, in battery materials $\left(\mathrm{LiCoO}_{2}\right)$, a red-shift of the $\mathrm{Co}-\mathrm{O}$ peaks has been observed upon Li deintercalation, ${ }^{45,84}$ which is linked to a structural change and to Co oxidation.

At each potential, the Raman spectrum is well represented by a sum of four Gaussian functions, whose relative intensities change with potential, while their position and full-width-at-half-maximum (FWHM) stay fixed. Aiming at a simple mathematical description of the spectral shape at each potential, the four peak positions and 4 widths were determined through a global (simultaneous) fit of all spectra resulting in excellent agreement between experimental and simulated spectra. An example of the spectral simulation is presented in Figs. 5(a) and 5(b). The percentage of the total peak area belonging to each Gaussian varies with potential, as shown in Fig. 5(c). We note that an assignment of the four Raman peaks to specific Raman modes or Co oxidation states is not possible. Inter alia because of $\mu-\mathrm{O}(\mathrm{H})$ bridging between $\mathrm{Co}^{\mathrm{II}}, \mathrm{Co}^{\mathrm{III}}$, and $\mathrm{Co}^{\mathrm{IV}}$ ions, each of the oxidation state species present in the CoCat could contribute to each of the four Gaussian-shaped Raman peaks, which were employed merely to describe the spectra by a limited set of parameters.

Even though there are four peaks in the Raman spectrum, there are only two independent spectral components of the potentialcontrolled changes. The reduction from 4 to 2 is due to the fact that (i) the areas of the $620 \mathrm{~cm}^{-1}$ and $539 \mathrm{~cm}^{-1}$ peaks have exactly the same potential dependence (Fig. S12) and (ii) the $584 \mathrm{~cm}^{-1}$ potential dependence can be obtained e.g., by subtracting the other three amplitudes from $100 \%$, due to normalization of the total peak area at each potential. The normalization of the total peak area was necessary due to the strong dependence of the signal intensity on the applied potential (see Sec. II D). 

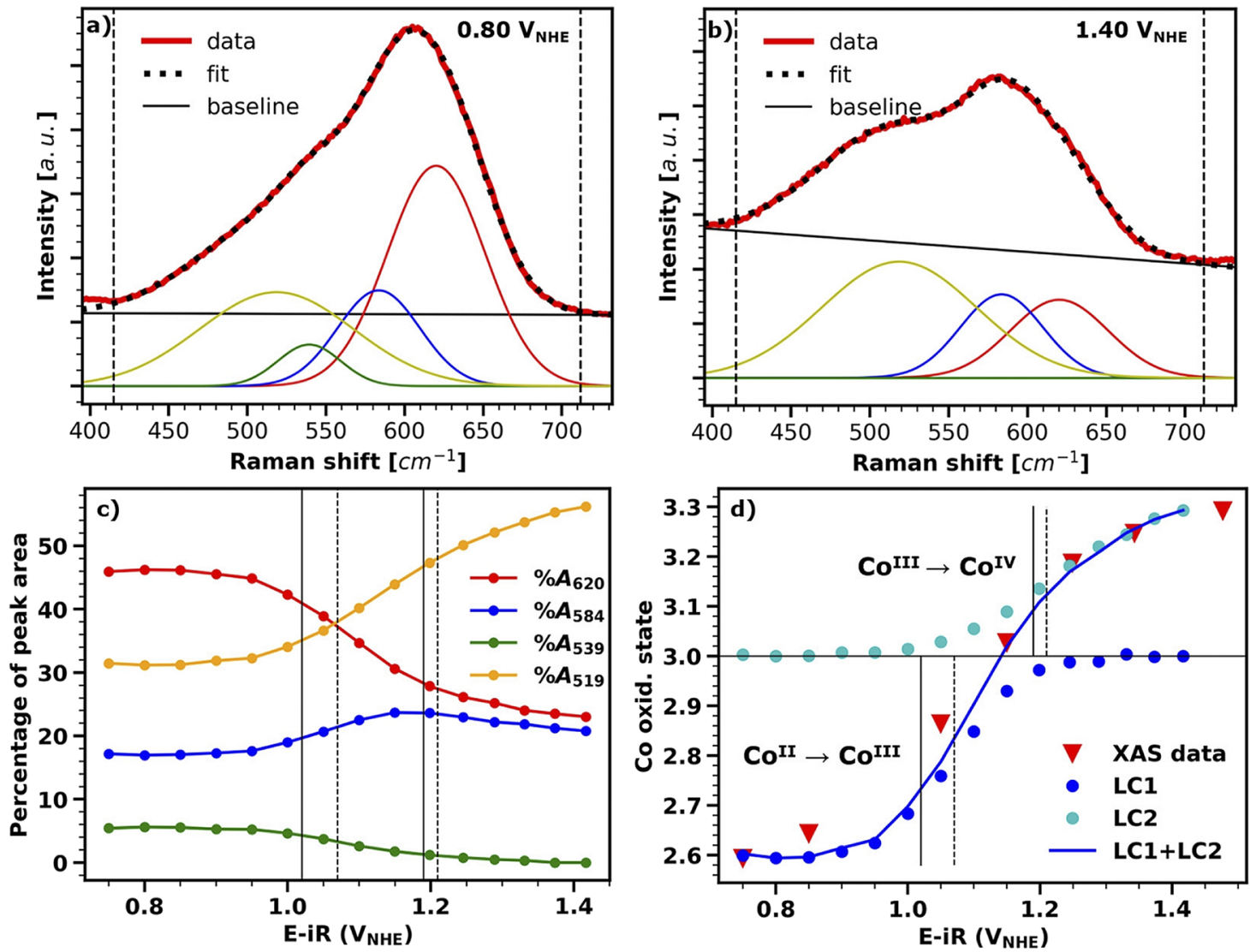

FIG. 5. [(a) and (b)] Simulation of the operando Raman spectra of CoCat in the region of Co-O vibrations. Spectra of the CoCat conditioned (equilibrated for 2 min) at (a) $0.80 \mathrm{~V}_{\text {NHE }}$ and (b) $1.40 \mathrm{~V}_{\text {NHE }}$ are shown as examples [all data in Fig. 2(a)]. Each Raman spectrum was simulated in the region $415 \mathrm{~cm}^{-1}$ to $712 \mathrm{~cm}^{-1}$ (fit range indicated by vertical dashed lines) with a linear baseline (black line) and four Gaussian functions (colored lines). The Gaussian functions have globally fitted positions $\left(620 \mathrm{~cm}^{-1}, 584\right.$ $\mathrm{cm}^{-1}, 539 \mathrm{~cm}^{-1}$, and $\left.519 \mathrm{~cm}^{-1}\right)$, globally fitted FWHMs $\left(63 \mathrm{~cm}^{-1}, 72 \mathrm{~cm}^{-1}, 47 \mathrm{~cm}^{-1}\right.$, and $116 \mathrm{~cm}^{-1}$, respectively), and varying amplitudes. (c) Percentage of the total area belonging to each Gaussian as a function of potential. (d) Comparison between the change in the Co oxidation state with potential and linear combinations of the Raman peak areas (LC1 and LC2). The percentage of peak areas for the $519 \mathrm{~cm}^{-1}$ and $620 \mathrm{~cm}^{-1}$ peaks was combined to represent the two individual Co oxidation-state transitions:

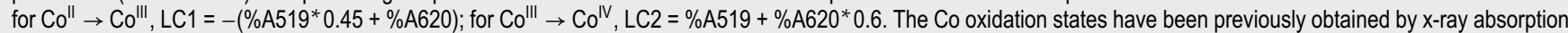
spectroscopy. ${ }^{27}$ The Raman data (LC1 and LC2) are shifted and rescaled to match the lowest and highest oxidation state previously determined by XAS. The vertical full lines indicate the midpoint potentials for the two Co oxidation-state transitions as determined previously. ${ }^{27}$ The vertical dotted lines indicate the potential at half-height (midpoint potential) for LC1 and LC2.

In the investigated potential range, three different Co species have been detected for CoCat: $\mathrm{Co}^{\mathrm{II}}, \mathrm{Co}{ }^{\mathrm{III}}$, and $\mathrm{Co}^{\mathrm{IV}} \cdot .^{10,27,47,89}$ For Co ions in the different oxidation states, different $\mathrm{Co}-\mathrm{O}$ bond lengths and possibly different protonation states of the oxygen ligands $(\mathrm{O}$, $\mathrm{OH}^{-1}$, or $\mathrm{H}_{2} \mathrm{O}$ ) are expected, suggesting that the three Co species exhibit different spectral fingerprints. The normalization of the total peak area needed here impedes the identification of specific spectra for each Co species. However, the two independent components of potential-controlled area changes can represent, through a linear combination, the two Co oxidation transitions occurring in this potential range $\left(\mathrm{Co}^{\mathrm{II}} \rightarrow \mathrm{Co}^{\mathrm{III}}\right.$ and $\left.\mathrm{Co}^{\mathrm{III}} \rightarrow \mathrm{Co}^{\mathrm{IV}}\right)$, as shown in Fig. 5(d).

In Fig. 5(d), the XAS data representing the change in the Co oxidation state is compared with two linear combinations of the potential-controlled area changes that plausibly reflect the
$\mathrm{Co}^{\mathrm{II}} \rightarrow \mathrm{Co}^{\mathrm{III}}(\mathrm{LC} 1)$ and $\mathrm{Co}^{\mathrm{III}} \rightarrow \mathrm{Co}^{\mathrm{IV}}$ (LC2) transitions. We note that the linear combinations of area-amplitudes are almost unique because significantly different combinations do not result in curves that could plausibly reflect the potential dependence of the Co oxidation states. The obtained curves were shifted and rescaled to match the lowest and highest oxidation state of each transition previously detected by XAS. ${ }^{27}$ Both redox transitions extend over a comparably large potential range and, thus, are significantly broader than expected for a purely Nernstian redox transition, as previously concluded based on XAS and further spectrochemical data and explained by the interaction between nearby Co ions in CoCat films. ${ }^{10,27}$ The midpoint potential of the two Co oxidation transitions obtained from the XAS data (vertical full lines in Fig. 5) is similar to the potential at half-height for LC1 and LC2 (vertical dotted lines). The difference could result from a comparably minor shift 
of midpoint potentials occurring during the CoCat operation (see Fig. S13).

In summary, the CoCat Raman spectra in the $\mathrm{Co}-\mathrm{O}$ region are well simulated by four Gaussian functions, whose areas change with the applied potential. The spectral changes reflect exactly two linearly independent components, which can be assigned to two Co redox transitions $\left(\mathrm{Co}^{\mathrm{II}} \rightarrow \mathrm{Co}^{\mathrm{III}}\right.$ and $\left.\mathrm{Co}^{\mathrm{III}} \rightarrow \mathrm{Co}^{\mathrm{IV}}\right)$. Thus, Raman spectroscopy facilitates monitoring of the redox transitions of the material. While XAS analyses typically result in determination of an average oxidation state only, Raman spectroscopy provides access to the individual redox transitions. This approach, likely, can be generalized to the study of other metal-oxide-based OER catalysts, where typically $\mathrm{M}^{\mathrm{I} / \mathrm{III}}$ and $\mathrm{M}^{\mathrm{III} / \mathrm{IV}}$ redox transitions are involved, as well as to battery materials.

\section{CONCLUSION}

Herein, we presented an approach for the investigation of materials in electrocatalytic OER via operando Raman spectroscopy. After a basic characterization of the Raman signals and possible artifact sources, we addressed changes in the electronic and atomic structure of the catalyst material that are of likely relevance for mechanistic insight in OER catalysis, as summarized in the following.

1. Two broad bands (around $877 \mathrm{~cm}^{-1}$ and $1077 \mathrm{~cm}^{-1}$ ) in the CoCat Raman spectrum are assignable to concentrated $\mathrm{H}_{\mathrm{x}} \mathrm{PO}_{4}{ }^{-}$ions (likely $\mathrm{x}=2$ ), possibly forming polyphosphates, which can favor proton transport through hydrogen bonds. Small changes in number and protonation states of the CoCatinternal phosphate ions depending on the applied electric potential would not be resolved in the present investigation.

2. In response to changes in the electric potential, an unexpected behavior was observed in both the Raman background intensity and the magnitude of Raman bands, both decreasing with increasingly positive electrode potentials. The unexpected behavior presumably does not represent a novel type of potential-dependent Raman enhancement, but rather variable re-absorption of the Raman light by the electrochromic CoCat material. The decrease in signal magnitude was shown to properly track the increase in the Co absorption coefficient and, thus, the increase in the average Co oxidation state (and consequently can be employed to track oxidation state changes).

3. At sub-catalytic and catalytic potentials, no evidence was found for accumulation of special, potentially reactive oxygen species [no evidence for $\mathrm{Co}=\mathrm{O}, \mathrm{Co}-\mathrm{O}^{\bullet}, \mathrm{Co}-\mathrm{O}-\mathrm{O}(\mathrm{H})$ ]. Our results neither can exclude a minor population with Raman intensities below the detection limit (see supplementary material for details on detection limit) nor are in conflict with reactive oxygen species that are transiently formed during $\mathrm{O}_{2}$-formation. We assign Raman bands in the spectra that might be related to such species $\left(800-1200 \mathrm{~cm}^{-1}\right)$ to two-phonon Raman scattering (twice the vibrational frequency of the main $\mathrm{Co}-\mathrm{O}$ bands).

4. Isotopic ${ }^{1} \mathrm{H} /{ }^{2} \mathrm{H}$ labeling enabled the detection of protonated/deprotonated oxygen species, presumably present as both, bridging $(\mathrm{Co}-\mathrm{OH}-\mathrm{Co})$ and terminal $(\mathrm{Co}-\mathrm{OH}$ and
$\mathrm{Co}-\mathrm{OH}_{2}$ ), ligands. At increasingly positive potentials, deprotonation of these species occurs, supporting proton-coupled electron transfer in the Co redox transitions.

5. Exposure of a ${ }^{16} \mathrm{O}$-CoCat to ${ }^{18} \mathrm{O}$-water showed that, also at catalytic potentials, only a minority fraction of the oxygen sites of the CoCat harbors exchangeable oxygen atoms. The majority fraction of non-exchangeable oxygen atoms most likely corresponds to bridging oxygen, which, consequently, are not the oxygen atoms that leave the catalyst in the form of dioxygen. The minority fraction of exchangeable ${ }^{16} \mathrm{O}$ likely corresponds to terminal Co ligands at the periphery of Co oxide fragments, suggesting that terminally coordinated water species are oxidized in OER by the CoCat material. We note that oxidation of non-coordinated water species also would not be in conflict with the herein reported results. This finding provides relevant support to recent mechanistic proposals based on massspectroscopy experiments ${ }^{68,90}$ and computational chemistry.

6. The normalized Raman spectra of CoCat in the $415 \mathrm{~cm}^{-1}$ to $712 \mathrm{~cm}^{-1}$ region, corresponding to $\mathrm{Co}-\mathrm{O}$ vibrations, were accurately described by four Gaussian peaks with potentialdependent areas, but only two independent components of potential-controlled area changes. In the potential range studied, two Co oxidation processes have been reported, i.e., $\mathrm{Co}^{\mathrm{II}} \rightarrow \mathrm{Co}^{\mathrm{III}}$ and $\mathrm{Co}^{\mathrm{III}} \rightarrow \mathrm{Co}^{\mathrm{IV}}$. Each of the Co oxidation reactions can be represented by a linear combination of the recorded spectral changes. Thus, Raman spectroscopy, unlike the published XAS studies, is able to distinguish the $\mathrm{Co}^{\mathrm{II}} \rightarrow \mathrm{Co}^{\mathrm{III}}$ from the $\mathrm{Co}^{\mathrm{III}} \rightarrow \mathrm{Co}^{\mathrm{IV}}$ oxidation.

In summary, electrochemical operando Raman spectroscopy, in conjunction with the described analysis approach, represents a promising tool in mechanistic investigations on OER catalysis and battery materials, including tracking of oxidation-state changes.

\section{SUPPLEMENTARY MATERIAL}

See the supplementary material for experimental details on materials; details on detection limit estimate; Raman and ATR spectroscopy; Fourier transforms of the XAS spectra for CoCat and $\mathrm{LiCoO}_{2}$; examples of Raman spectra with laser-heating damage; Raman spectrum of CoCat operated in KBi; IR-ATR spectra for CoCat; pictures of the Raman electrochemical cell; Raman spectra for a thin CoCat film and a bare Pt substrate operated at different potentials; potential dependence of the background signal for a thin CoCat film; extended Raman spectra of CoCat $\left(150-3600 \mathrm{~cm}^{-1}\right.$ region); tables and exemplary figures with details of Raman spectra simulation; Raman spectra for CoCat with different laser-excitation wavelength; and cyclic voltammetry scans collected before and after the potential stair experiment.

\section{ACKNOWLEDGMENTS}

Financial support was provided by the German Federal Ministry of Education and Research (Bundesministerium für Bildung und Forschung, CO2EKAT Project No. 03SF0523B). Moreover, this study was funded by the Deutsche Forschungsgemeinschaft (DFG, German Research Foundation) under Germany's Excellence Strategy - EXC 2008-390540038-UniSysCat. The authors thank Dr. 
Stefan Mebs (FU Berlin) for his support in the operation of the Raman spectrometer, Dr. Petko Chernev (FU Berlin, now Uppsala University) for writing data analysis programs, and Dr. Marcel Risch (FU Berlin, now Helmholtz-Zentrum Berlin) for the collection of the XAS spectrum of $\mathrm{LiCoO}_{2}$.

\section{DATA AVAILABILITY}

All relevant data are presented in the article or as supplementary material.

\section{REFERENCES}

${ }^{1}$ D. Abbott, "Keeping the energy debate clean: How do we supply the World's energy needs?," Proc. IEEE 98(1), 42-66 (2010).

${ }^{2}$ N. Armaroli and V. Balzani, "Solar electricity and solar fuels: Status and perspectives in the context of the energy transition," Chem, - Eur. J. 22(1), 32-57 (2016).

${ }^{3}$ O. Ellabban, H. Abu-Rub, and F. Blaabjerg, "Renewable energy resources: Current status, future prospects and their enabling technology," Renewable Sustainable Energy Rev. 39, 748-764 (2014).

${ }^{4}$ M. K. Brennaman, R. J. Dillon, L. Alibabaei, M. K. Gish, C. J. Dares, D. L. Ashford, R. L. House, G. J. Meyer, J. M. Papanikolas, and T. J. Meyer, "Finding the way to solar fuels with dye-sensitized photoelectrosynthesis cells," J. Am. Chem. Soc. 138(40), 13085-13102 (2016).

${ }^{5}$ N.-T. Suen, S.-F. Hung, Q. Quan, N. Zhang, Y.-J. Xu, and H. M. Chen, "Electrocatalysis for the oxygen evolution reaction: Recent development and future perspectives," Chem. Soc. Rev. 46(2), 337-365 (2017).

${ }^{6}$ J. D. Blakemore, R. H. Crabtree, and G. W. Brudvig, "Molecular catalysts for water oxidation," Chem. Rev. 115(23), 12974-13005 (2015).

${ }^{7}$ J. Li, R. Güttinger, R. Moré, F. Song, W. Wan, and G. R. Patzke, "Frontiers of water oxidation: The quest for true catalysts," Chem. Soc. Rev. 46(20), 6124-6147 (2017).

${ }^{8}$ C. H. M. van Oversteeg, H. Q. Doan, F. M. F. de Groot, and T. Cuk, "In situ $\mathrm{X}$-ray absorption spectroscopy of transition metal based water oxidation catalysts," Chem. Soc. Rev. 46, 102-125 (2017).

${ }^{9}$ Y. Surendranath, M. W. Kanan, and D. G. Nocera, "Mechanistic studies of the oxygen evolution reaction by a cobalt-phosphate catalyst at neutral $\mathrm{pH}$, J. $\mathrm{Jm}$. Chem. Soc. 132(46), 16501-16509 (2010).

${ }^{10}$ M. Risch, F. Ringleb, M. Kohlhoff, P. Bogdanoff, P. Chernev, I. Zaharieva, and H. Dau, "Water oxidation by amorphous cobalt-based oxides: In situ tracking of redox transitions and mode of catalysis," Energy Environ. Sci. 8(2), 661-674 (2015).

${ }^{11}$ R. D. L. Smith, C. Pasquini, S. Loos, P. Chernev, K. Klingan, P. Kubella, M. R. Mohammadi, D. Gonzalez-Flores, and H. Dau, "Spectroscopic identification of active sites for the oxygen evolution reaction on iron-cobalt oxides," Nat. Commun. 8(1), 2022 (2017)

${ }^{12} \mathrm{O}$. Zandi and T. W. Hamann, "Determination of photoelectrochemical water oxidation intermediates on haematite electrode surfaces using operando infrared spectroscopy," Nat. Chem. 8(8), 778-783 (2016).

${ }^{13}$ L. Francàs, S. Corby, S. Selim, D. Lee, C. A. Mesa, R. Godin, E. Pastor, I. E. L. Stephens, K.-S. Choi, and J. R. Durrant, "Spectroelectrochemical study of water oxidation on nickel and iron oxyhydroxide electrocatalysts," Nat. Commun. 10(1), 5208 (2019)

${ }^{14}$ V. R. Stamenkovic, D. Strmcnik, P. P. Lopes, and N. M. Markovic, "Energy and fuels from electrochemical interfaces," Nat. Mater. 16, 57-69 (2017).

${ }^{15}$ Z. W. Seh, J. Kibsgaard, C. F. Dickens, I. Chorkendorff, J. K. Nørskov, and T. F. Jaramillo, "Combining theory and experiment in electrocatalysis: Insights into materials design," Science 355(6321), eaad4998 (2017).

${ }^{16}$ B. M. Hunter, W. Hieringer, J. R. Winkler, H. B. Gray, and A. M. Müller, "Effect of interlayer anions on [NiFe]-LDH nanosheet water oxidation activity," Energy Environ. Sci. 9, 1734-1743 (2016).

${ }^{17}$ I. C. Man, H. Y. Su, F. Calle-Vallejo, H. A. Hansen, J. I. Martínez, N. G. Inoglu, J. Kitchin, T. F. Jaramillo, J. K. Nørskov, and J. Rossmeisl, "Universality in oxygen evolution electrocatalysis on oxide surfaces," ChemCatChem 3(7), 11591165 (2011).

${ }^{18}$ B. M. Hunter, H. B. Gray, and A. M. Müller, "Earth-abundant heterogeneous water oxidation catalysts," Chem. Rev. 116, 14120-14136 (2016).

${ }^{19}$ H. J. King, S. A. Bonke, S. L. Y. Chang, L. Spiccia, B. Johannessen, and R. K. Hocking, "Engineering disorder into heterogenite-like cobalt oxides by phosphate doping: Implications for the design of water-oxidation catalysts," ChemCatChem 9, 511-521 (2017).

${ }^{20}$ M. Görlin, J. F. de Araujo, H. Schmies, D. Bernsmeier, S. Dresp, M. Gliech, Z. Jusys, P. Chernev, R. Kraehnert, H. Dau, and P. Strasser, "Tracking catalyst redox states and reaction dynamics in $\mathrm{Ni}-\mathrm{Fe}$ oxyhydroxide oxygen evolution reaction electrocatalysts: The role of catalyst support and electrolyte pH," J. Am. Chem. Soc. 139(5), 2070-2082 (2017).

${ }^{21}$ M. W. Kanan and D. G. Nocera, "In situ formation of an oxygen-evolving catalyst in neutral water containing phosphate and $\mathrm{Co}^{2+}$," Science 321(5892), 1072-1075 (2008).

${ }^{22}$ M. S. Burke, M. G. Kast, L. Trotochaud, A. M. Smith, and S. W. Boettcher, "Cobalt-iron (oxy)hydroxide oxygen evolution electrocatalysts: The role of structure and composition on activity, stability, and mechanism," J. Am. Chem. Soc. 137(10), 3638-3648 (2015).

${ }^{23}$ R. D. L. Smith, M. S. Prévot, R. D. Fagan, S. Trudel, and C. P. Berlinguette, "Water oxidation catalysis: Electrocatalytic response to metal stoichiometry in amorphous metal oxide films containing iron, cobalt, and nickel," J. Am. Chem. Soc. 135(31), 11580-11586 (2013).

${ }^{24}$ I. Roger, M. A. Shipman, and M. D. Symes, "Earth-abundant catalysts for electrochemical and photoelectrochemical water splitting," Nat. Rev. Chem. 1, 0003 (2017).

${ }^{25}$ I. Zaharieva, D. González-Flores, B. Asfari, C. Pasquini, M. R. Mohammadi, K. Klingan, I. Zizak, S. Loos, P. Chernev, and H. Dau, "Water oxidation catalysis role of redox and structural dynamics in biological photosynthesis and inorganic manganese oxides," Energy Environ. Sci. 9, 2433-2443 (2016).

${ }^{26}$ D. González-Flores, K. Klingan, P. Chernev, S. Loos, M. R. Mohammadi, C. Pasquini, P. Kubella, I. Zaharieva, R. D. L. Smith, and H. Dau, "Nickel-iron catalysts for electrochemical water oxidation - redox synergism investigated by in situ X-ray spectroscopy with millisecond time resolution," Sustainable Energy Fuels 2(9), 1986-1994 (2018).

${ }^{27}$ C. Pasquini, I. Zaharieva, D. González-Flores, P. Chernev, M. R. Mohammadi, L. Guidoni, R. D. L. Smith, and H. Dau, "Isotope effects reveal factors controlling catalytic activity in CO-based oxides for water oxidation," J. Am. Chem. Soc. 141(7), 2938-2948 (2019).

${ }^{28}$ M. V. Abrashev, P. Chernev, P. Kubella, M. R. Mohammadi, C. Pasquini, H. Dau, and I. Zaharieva, "Origin of the heat-induced improvement of catalytic activity and stability of $\mathrm{MnO}_{x}$ electrocatalysts for water oxidation," J. Mater. Chem. A 7(28), 17022-17036 (2019).

${ }^{29}$ J. Jiang, Y. Li, J. Liu, X. Huang, C. Yuan, and X. W. D. Lou, "Recent advances in metal oxide-based electrode architecture design for electrochemical energy storage," Adv. Mater. 24(38), 5166-5180 (2012).

${ }^{30}$ W. Liu, P. Oh, X. Liu, M.-J. Lee, W. Cho, S. Chae, Y. Kim, and J. Cho, "Nickelrich layered lithium transition-metal oxide for high-energy lithium-ion batteries," Angew. Chem., Int. Ed. 54(15), 4440-4457 (2015).

${ }^{31}$ B. Banov, J. Bourilkov, and M. Mladenov, "Cobalt stabilized layered lithiumnickel oxides, cathodes in lithium rechargeable cells," J. Power Sources 54(2), 268270 (1995).

${ }^{32}$ M. M. Thackeray, "Manganese oxides for lithium batteries," Prog. Solid State Chem. 25(1), 1-71 (1997).

${ }^{33}$ A. K. Padhi, "Phospho-olivines as positive-electrode materials for rechargeable lithium batteries," J. Electrochem. Soc. 144(4), 1188 (1997).

${ }^{34}$ M. Risch, V. Khare, I. Zaharieva, L. Gerencser, P. Chernev, and H. Dau, "Cobaltoxo core of a water-oxidizing catalyst film," J. Am. Chem. Soc. 131(20), 6936-6937 (2009).

${ }^{35}$ M. Risch, K. Klingan, J. Heidkamp, D. Ehrenberg, P. Chernev, I. Zaharieva, and H. Dau, "Nickel-oxido structure of a water-oxidizing catalyst film," Chem. Commun. 47(43), 11912-11914 (2011).

${ }^{36}$ J. Park, H. Kim, K. Jin, B. J. Lee, Y.-S. Park, H. Kim, I. Park, K. D. Yang, H.-Y. Jeong, J. Kim, K. T. Hong, H. W. Jang, K. Kang, and K. T. Nam, “A new water 
oxidation catalyst: Lithium manganese pyrophosphate with tunable Mn valency," J. Am. Chem. Soc. 136(11), 4201-4211 (2014).

${ }^{37}$ D. K. Bediako, B. Lassalle-Kaiser, Y. Surendranath, J. Yano, V. K. Yachandra, and D. G. Nocera, "Structure-activity correlations in a nickel-borate oxygen evolution catalyst," J. Am. Chem. Soc. 134(15), 6801-6809 (2012).

${ }^{38}$ I. Zaharieva, P. Chernev, M. Risch, K. Klingan, M. Kohlhoff, A. Fischer, and H. Dau, "Electrosynthesis, functional and structural characterization of a wateroxidizing manganese oxide," Energy Environ. Sci. 5, 7081-7089 (2012).

${ }^{39}$ F. Lin, Y. Liu, X. Yu, L. Cheng, A. Singer, O. G. Shpyrko, H. L. Xin, N. Tamura, C. Tian, T.-C. Weng, X.-Q. Yang, Y. S. Meng, D. Nordlund, W. Yang, and M. M. Doeff, "Synchrotron X-ray analytical techniques for studying materials electrochemistry in rechargeable batteries," Chem. Rev. 117(21), 13123-13186 (2017).

${ }^{40}$ A. Ito, Y. Sato, T. Sanada, M. Hatano, H. Horie, and Y. Ohsawa, "In situ X-ray absorption spectroscopic study of Li-rich layered cathode material $\mathrm{Li}\left[\mathrm{Ni}_{0.17} \mathrm{Li}_{0.2} \mathrm{Co}_{0.07} \mathrm{Mn}_{0.56}\right] \mathrm{O}_{2}$," J. Power Sources 196(16), 6828-6834 (2011).

${ }^{41}$ M. A. Lowe, J. Gao, and H. D. Abruña, "In operando X-ray studies of the conversion reaction in $\mathrm{Mn}_{3} \mathrm{O}_{4}$ lithium battery anodes," J. Mater. Chem. A 1(6), 2094-2103 (2013).

${ }^{42}$ H.-Y. Wang, S.-F. Hung, Y.-Y. Hsu, L. Zhang, J. Miao, T.-S. Chan, Q. Xiong, and B. Liu, "In situ spectroscopic identification of $\mu$-OO bridging on spinel $\mathrm{Co}_{3} \mathrm{O}_{4}$ water oxidation electrocatalyst," J. Phys. Chem. Lett. 7(23), 4847-4853 (2016).

${ }^{43}$ I. Y. Ahmet, Y. Ma, J.-W. Jang, T. Henschel, B. Stannowski, T. Lopes, A. Vilanova, A. Mendes, F. F. Abdi, and R. van de Krol, "Demonstration of a $50 \mathrm{~cm}^{2} \mathrm{BiVO}_{4}$ tandem photoelectrochemical-photovoltaic water splitting device," Sustainable Energy Fuels 3(9), 2366-2379 (2019).

${ }^{44}$ U. Bergmann and P. Glatzel, "X-ray emission spectroscopy," Photosynth. Res. 102(2-3), 255-266 (2009).

${ }^{45} \mathrm{M}$. Inaba, Y. Iriyama, Z. Ogumi, Y. Todzuka, and A. Tasaka, "Raman study of layered rock-salt $\mathrm{LiCoO} 2$ and its electrochemical lithium deintercalation," J. Raman Spectrosc. 28(8), 613-617 (1997).

${ }^{46}$ T. Burdyny, P. J. Graham, Y. Pang, C.-T. Dinh, M. Liu, E. H. Sargent, and D. Sinton, "Nanomorphology-enhanced gas-evolution intensifies $\mathrm{CO}_{2}$ reduction electrochemistry," ACS Sustainable Chem. Eng. 5(5), 4031-4040 (2017).

${ }^{47}$ J. B. Gerken, J. G. McAlpin, J. Y. C. Chen, M. L. Rigsby, W. H. Casey, R. D. Britt, and S. S. Stahl, "Electrochemical water oxidation with cobalt-based electrocatalysts from $\mathrm{pH} 0-14$ : The thermodynamic basis for catalyst structure, stability, and activity," J. Am. Chem. Soc. 133(36), 14431-14442 (2011).

${ }^{48}$ A. Bergmann, T. E. Jones, E. Martinez Moreno, D. Teschner, P. Chernev, M. Gliech, T. Reier, H. Dau, and P. Strasser, "Unified structural motifs of the catalytically active state of $\mathrm{Co}$ (oxyhydr)oxides during the electrochemical oxygen evolution reaction," Nat. Catal. 1(9), 711-719 (2018).

${ }^{49}$ M. Zhang, M. de Respinis, and H. Frei, "Time-resolved observations of water oxidation intermediates on a cobalt oxide nanoparticle catalyst," Nat. Chem. $6(4)$, 362-367 (2014).

${ }^{50}$ M. Bajdich, M. García-Mota, A. Vojvodic, J. K. Nørskov, and A. T. Bell, "Theoretical investigation of the activity of cobalt oxides for the electrochemical oxidation of water," J. Am. Chem. Soc. 135(36), 13521-13530 (2013).

${ }^{51}$ K. Klingan, F. Ringleb, I. Zaharieva, J. Heidkamp, P. Chernev, D. GonzalezFlores, M. Risch, A. Fischer, and H. Dau, "Water oxidation by amorphous cobalt-based oxides: Volume activity and proton transfer to electrolyte bases," ChemSusChem 7(5), 1301-1310 (2014).

${ }^{52}$ D. K. Bediako, C. Costentin, E. C. Jones, D. G. Nocera, and J.-M. Savéant, "Proton-electron transport and transfer in electrocatalytic films. Application to a cobalt-based $\mathrm{O}_{2}$-evolution catalyst," J. Am. Chem. Soc. 135(28), 10492-10502 (2013).

${ }^{53}$ C. Costentin, T. R. Porter, and J.-M. Savéant, "Conduction and reactivity in heterogeneous-molecular catalysis: New insights in water oxidation catalysis by phosphate cobalt oxide films," J. Am. Chem. Soc. 138(17), 5615-5622 (2016).

${ }^{54}$ P. Du, O. Kokhan, K. W. Chapman, P. J. Chupas, and D. M. Tiede, "Elucidating the domain structure of the cobalt oxide water splitting catalyst by X-ray pair distribution function analysis," J. Am. Chem. Soc. 134(27), 11096-11099 (2012).

${ }^{55}$ G. Kwon, H. Jang, J.-S. Lee, A. Mane, D. J. Mandia, S. R. Soltau, L. M. Utschig, A. B. F. Martinson, D. M. Tiede, H. Kim, and J. Kim, "Resolution of electronic and structural factors underlying oxygen-evolving performance in amorphous cobalt oxide catalysts," J. Am. Chem. Soc. 140(34), 10710-10720 (2018).

${ }^{56}$ B. S. Yeo, S. L. Klaus, P. N. Ross, R. A. Mathies, and A. T. Bell, "Identification of hydroperoxy species as reaction intermediates in the electrochemical evolution of oxygen on gold," ChemPhysChem 11(9), 1854-1857 (2010).

${ }^{57} \mathrm{~B}$. Rivas-Murias and V. Salgueiriño, "Thermodynamic $\mathrm{CoO}-\mathrm{Co}_{3} \mathrm{O}_{4}$ crossover using Raman spectroscopy in magnetic octahedron-shaped nanocrystals," J. Raman Spectrosc. 48(6), 837-841 (2017).

${ }^{58}$ G. E. Walrafen, "Raman spectral studies of water structure," J. Chem. Phys. 40(11), 3249-3256 (1964).

${ }^{59}$ L. P. Heighton, M. Zimmerman, C. P. Rice, E. E. Codling, J. A. Tossell, and W. F. Schmidt, "Quantification of inositol hexa-kis phosphate in environmental samples," Open J. Soil Sci. 2, 55-63 (2012).

${ }^{60} \mathrm{~K}$. Yang, R. Kas, and W. A. Smith, "In situ infrared spectroscopy reveals persistent alkalinity near electrode surfaces during $\mathrm{CO}_{2}$ electroreduction," J. Am. Chem. Soc. 141(40), 15891-15900 (2019).

${ }^{61}$ M. Dunwell, X. Yang, B. P. Setzler, J. Anibal, Y. Yan, and B. Xu, "Examination of near-electrode concentration gradients and kinetic impacts on the electrochemical reduction of $\mathrm{CO}_{2}$ using surface-enhanced infrared spectroscopy," ACS Catal. 8(5), 3999-4008 (2018).

${ }^{62}$ J. Villalobos, D. González-Flores, K. Klingan, P. Chernev, P. Kubella, R. Urcuyo, C. Pasquini, M. R. Mohammadi, R. D. L. Smith, M. L. Montero, and H. Dau, "Structural and functional role of anions in electrochemical water oxidation probed by arsenate incorporation into cobalt-oxide materials," Phys. Chem. Chem. Phys. 21(23), 12485-12493 (2019).

${ }^{63}$ C. M. Preston and W. A. Adams, "A laser Raman spectroscopic study of aqueous orthophosphate salts," J. Phys. Chem. 83(7), 814-821 (1979).

${ }^{64}$ F. Rashchi and J. A. Finch, "Polyphosphates: A review their chemistry and application with particular reference to mineral processing," Miner. Eng. 13(10), 1019-1035 (2000).

${ }^{65}$ C. J. Eom and J. Suntivich, "In situ stimulated Raman spectroscopy reveals the phosphate network in the amorphous cobalt oxide catalyst and its role in the catalyst formation," J. Phys. Chem. C 123(48), 29284-29290 (2019).

${ }^{66} \mathrm{Y}$. Abe, "Protonic conduction in phosphate glasses," J. Electrochem. Soc. 141(6), L64 (1994).

${ }^{67}$ Y. Li, W. Qiu, F. Qin, H. Fang, V. G. Hadjiev, D. Litvinov, and J. Bao, "Identification of cobalt oxides with Raman scattering and fourier transform infrared spectroscopy," J. Phys. Chem. C 120(8), 4511-4516 (2016).

${ }^{68}$ A. M. Ullman, C. N. Brodsky, N. Li, S.-L. Zheng, and D. G. Nocera, "Probing edge site reactivity of oxidic cobalt water oxidation catalysts," J. Am. Chem. Soc. 138, 4229-4236 (2016).

${ }^{69}$ B. S. Yeo and A. T. Bell, "Enhanced activity of gold-supported cobalt oxide for the electrochemical evolution of oxygen," J. Am. Chem. Soc. 133(14), 5587-5593 (2011).

${ }^{70}$ A. Rougier, G. A. Nazri, and C. Julien, "Vibrational spectroscopy and electrochemical properties of $\mathrm{LiNi}_{0.7} \mathrm{Co}_{0.3} \mathrm{O}_{2}$ cathode material for rechargeable lithium batteries," Ionics 3(3), 170-176 (1997).

${ }^{71}$ J. A. Koza, C. M. Hull, Y.-C. Liu, and J. A. Switzer, "Deposition of $-\mathrm{Co}(\mathrm{OH})_{2}$ films by electrochemical reduction of tris(ethylenediamine)cobalt(III) in alkaline solution," Chem. Mater. 25(9), 1922-1926 (2013).

${ }^{72}$ Z. Pavlovic, C. Ranjan, Q. Gao, M. van Gastel, and R. Schlögl, "Probing the structure of a water-oxidizing anodic iridium oxide catalyst using Raman spectroscopy," ACS Catal. 6(12), 8098-8105 (2016).

${ }^{73}$ O. Diaz-Morales, D. Ferrus-Suspedra, and M. T. M. Koper, "The importance of nickel oxyhydroxide deprotonation on its activity towards electrochemical water oxidation," Chem. Sci. 7(4), 2639-2645 (2016).

${ }^{74}$ R. D. L. Smith and C. P. Berlinguette, "Accounting for the dynamic oxidative behavior of nickel anodes," J. Am. Chem. Soc. 138(5), 1561-1567 (2016).

${ }^{75}$ G. Mattioli, P. Giannozzi, A. Amore Bonapasta, and L. Guidoni, "Reaction pathways for oxygen evolution promoted by cobalt catalyst," J. Am. Chem. Soc. 135(41), 15353-15363 (2013).

${ }^{76}$ C. Costentin and D. G. Nocera, "Self-healing catalysis in water," Proc. Natl. Acad. Sci. U. S. A. 114(51), 13380-13384 (2017).

${ }^{77}$ G. Mattioli, M. Risch, M. A. Bonapasta, H. Dau, and L. Guidoni, "Protonation states in a cobalt-oxide catalyst for water oxidation: Fine comparison of 
ab initio molecular dynamics and X-ray absorption spectroscopy results," Phys. Chem. Chem. Phys. 13, 15437-15441 (2011).

${ }^{78}$ D. R. Weinberg, C. J. Gagliardi, J. F. Hull, C. F. Murphy, C. A. Kent, B. C. Westlake, A. Paul, D. H. Ess, D. G. McCafferty, and T. J. Meyer, "Proton-coupled electron transfer," Chem. Rev. 112(7), 4016-4093 (2012).

${ }^{79}$ H. Dau, C. Limberg, T. Reier, M. Risch, S. Roggan, and P. Strasser, "The mechanism of water oxidation: From electrolysis via homogeneous to biological catalysis," ChemCatChem 2(7), 724-761 (2010).

${ }^{80} \mathrm{~T}$. Ohzuku, "Solid-state redox reactions of $\mathrm{LiCoO}_{2}(\mathrm{R} 3 \mathrm{~m})$ for 4 volt secondary lithium cells," J. Electrochem. Soc. 141(11), 2972 (1994).

${ }^{81}$ Z. Pavlovic, C. Ranjan, M. van Gastel, and R. Schlögl, "The active site for the water oxidising anodic iridium oxide probed through in situ Raman spectroscopy," Chem. Commun. 53(92), 12414-12417 (2017).

${ }^{82}$ M. W. Kanan, J. Yano, Y. Surendranath, M. Dincă, V. K. Yachandra, and D. G. Nocera, "Structure and valency of a cobalt-phosphate water oxidation catalyst determined by in situ X-ray spectroscopy," J. Am. Chem. Soc. 132(39), 13692-13701 (2010).

${ }^{83}$ A. Grimaud, O. Diaz-Morales, B. Han, W. T. Hong, Y.-L. Lee, L. Giordano, K. A. Stoerzinger, M. T. M. Koper, and Y. Shao-Horn, "Activating lattice oxygen redox reactions in metal oxides to catalyze oxygen evolution," Nat. Chem. 9(5), 457-465 (2017).
${ }^{84}$ Y. Matsuda, N. Kuwata, T. Okawa, A. Dorai, O. Kamishima, and J. Kawamura, "In situ Raman spectroscopy of $\mathrm{Li} \mathrm{CoO}_{2}$ cathode in $\mathrm{Li}_{2} / \mathrm{Li}_{3} \mathrm{PO}_{4} / \mathrm{LiCoO}_{2}$ all-solidstate thin-film lithium battery," Solid State Ionics 335, 7-14 (2019).

${ }^{85} \mathrm{~L}$. Trotochaud, T. J. Mills, and S. W. Boettcher, "An optocatalytic model for semiconductor-catalyst water-splitting photoelectrodes based on in situ optical measurements on operational catalysts," J. Phys. Chem. Lett. 4(6), 931-935 (2013). ${ }^{86}$ C. N. Polo da Fonseca, M.-A. De Paoli, and A. Gorenstein, "Electrochromism in cobalt oxide thin films grown by anodic electroprecipitation," Sol. Energy Mater. Sol. Cells 33(1), 73-81 (1994).

${ }^{87}$ S. Jiang, K. Klingan, C. Pasquini, and H. Dau, "New aspects of operando Raman spectroscopy applied to electrochemical $\mathrm{CO}_{2}$ reduction on $\mathrm{Cu}$ foams," J. Chem. Phys. 150(4), 041718 (2019).

${ }^{88}$ S. Mahajan, R. M. Cole, J. D. Speed, S. H. Pelfrey, A. E. Russell, P. N. Bartlett, S. M. Barnett, and J. J. Baumberg, "Understanding the surface-enhanced Raman spectroscopy “background”," J. Phys. Chem. C 114(16), 7242-7250 (2010).

${ }^{89}$ J. G. McAlpin, Y. Surendranath, M. Dincă, T. A. Stich, S. A. Stoian, W. H. Casey, D. G. Nocera, and R. D. Britt, "EPR evidence for $\mathrm{Co}(\mathrm{IV})$ species produced during water oxidation at neutral pH," J. Am. Chem. Soc. 132(20), 6882-6883 (2010).

${ }^{90}$ S. Koroidov, M. F. Anderlund, S. Styring, A. Thapper, and J. Messinger, "First turnover analysis of water-oxidation catalyzed by Co-oxide nanoparticles," Energy Environ. Sci. 8, 2492-2503 (2015). 